\title{
Changes in northern hemisphere temperature variability shaped by regional warming patterns
}

Article

Accepted Version

Tamarin-Brodsky, T., Hodges, K., Hoskins, B. J. and Shepherd, T. G. (2020) Changes in northern hemisphere temperature variability shaped by regional warming patterns. Nature Geoscience, 13. pp. 414-421. ISSN 1752-0894 doi: https://doi.org/10.1038/s41561-020-0576-3 Available at https://centaur.reading.ac.uk/89972/

It is advisable to refer to the publisher's version if you intend to cite from the work. See Guidance on citing.

To link to this article DOI: http://dx.doi.org/10.1038/s41561-020-0576-3

Publisher: Nature Publishing Group

All outputs in CentAUR are protected by Intellectual Property Rights law, including copyright law. Copyright and IPR is retained by the creators or other copyright holders. Terms and conditions for use of this material are defined in the End User Agreement.

www.reading.ac.uk/centaur 
Central Archive at the University of Reading

Reading's research outputs online 


\section{Changes in northern hemisphere temperature variability shaped by regional warming patterns}

${ }_{3}$ Talia Tamarin-Brodsky ${ }^{1}$, Kevin Hodges ${ }^{1,2}$, Brian J. Hoskins ${ }^{1}$, and Theodore G. Shepherd ${ }^{1}$

$4 \quad{ }^{1}$ Department of Meteorology, University of Reading, Reading, United Kingdom

${ }_{5}^{2}$ National Centre for Atmospheric Science, University of Reading, Reading, UK

Global warming involves changes not only in the mean atmospheric temperature, but also in its variability and extremes. Here we use a feature-tracking technique to investigate the dynamical contribution to temperature anomalies in the northern hemisphere in CMIP5 climate-change simulations. We develop a simple theory to explain how temperature variance and skewness changes are generated dynamically from mean temperature gradient changes, and demonstrate the crucial role of regional warming patterns in shaping the distinct response of cold and warm anomalies. We also show that skewness changes must be taken into account, in addition to variance changes, in order to correctly capture the projected temperature variability response. These changes in variability may impact humans, agriculture and animals, as they experience not only a warmer mean climate, but also a new likelihood of temperature anomalies within that climate.

Atmospheric temperature is often described as the mean temperature and its variance (Fig. 1), the latter measuring the strength of fluctuations around the average temperature. Assuming a Gaussian distribution of the underlying Probability Density Function (PDF), the mean and variance capture the essence of the observed temperature variability ${ }^{1-3}$. However, there is increasing evidence 
that temperature PDFs are characterized by nonzero skewness, which implies a non-Gaussian temperature distribution ${ }^{4-12}$. Skewness, defined as $S=\overline{T^{\prime 3}} /\left(\overline{T^{\prime 2}}\right)^{\frac{3}{2}}$ (where bar signifies a seasonallyvarying time average and $T^{\prime}$ denotes the temperature anomalies) measures the asymmetry between the positive and negative tails of the PDF, and is positive in regions where large warm anomalies are more frequent, and negative in regions where large cold anomalies are more frequent. Therefore, the spatial structure of skewness (Fig. 2) has important implications for regional climate and weather ${ }^{5,7,9,13-19}$.

Under global warming, the spatial distribution of the mean temperature and its variability are projected to change, leading to significant climate impacts ${ }^{20,21}$. Many studies have examined the mean temperature response as well as its variance and extremes using climate change

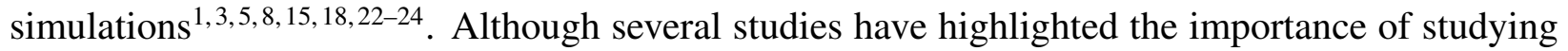
the response of temperature skewness to climate change $\mathrm{e}^{6,10,11,13,15,18,21,25-29}$, changes in extreme cold and warm temperature events are still typically attributed to changes in the mean and variance alone (e.g., Figure 1.8 in the 5th IPCC report ${ }^{30}$ ). Here we take a dynamical approach to study temperature variability in the Northern Hemisphere $(\mathrm{NH})$, employing a Lagrangian feature-tracking algorithm to identify and track temperature anomalies. This allows us to directly evaluate the separate changes in the intensity of cold and warm anomalies.

To concentrate on the dynamical origin of the temperature changes, we examine the $850 \mathrm{hPa}$ level rather than the surface anomalies. The $850 \mathrm{hPa}$ level is a widely-used near-surface level ${ }^{3,10,24}$ as it is typically above the boundary layer, but still highly correlated with the surface during strong 
cold and warm temperature events (Extended Data Fig. 1). The relation to surface temperature changes is discussed in the final section.

\section{Projected temperature changes}

We first present the Eulerian temperature variability changes for winter (DJF) and summer (JJA), for the ensemble-averaged CMIP5 response for the mean temperature, variance and skewness (see Methods). The $850 \mathrm{hPa}$ wintertime mean temperature exhibits an excess warming in the high-latitude NH (Fig. 1c), implying a weakening of the meridional (north-south) temperature gradient $^{3,22,24}$ (Extended Data Fig. 4). In addition, the relatively colder continental land masses warm more rapidly than the oceans, so the zonal (east-west) temperature gradients also decrease over most of the NH. To first order, the general decrease of the temperature gradients in winter leads to a decrease in the temperature variance, since by advection arguments a weaker gradient implies weaker anomalies ${ }^{3,22,24}$. However, some regions such as the Mediterranean and the Iberian Peninsula exhibit a slight variance increase (Fig. 1d). In summer, the already warmer continents warm more rapidly than the oceans (Fig. $1 \mathrm{~g}$ ), such that the zonal temperature gradients increase ${ }^{24}$ (Extended Data Fig. 4). There is less agreement between the models regarding the sign of the variance change in summer, but a robust increase in variance is projected over central Europe $\mathrm{e}^{5,31}$ (Fig. 1h).

The temperature skewness changes provide further important information. For example, the generally positive skewness change over most of the NH during winter (Fig. 2c) implies, together 
with the variance decrease, that it is the cold anomalies that weaken the most. In summer, the increase in variance over central Europe is accompanied by a negative skewness change in the southern regions, and a slight positive skewness change in the northeastern regions (Fig. 2g). Hence, it is mainly the cold anomalies that intensify in southern Europe, and mainly the warm anomalies that intensify in northeastern Europe.

\section{Lagrangian temperature variability}

Lagrangian feature-tracking is a commonly-applied technique in the field of stormtracks, used for studying cyclones and anticyclones ${ }^{32}$, but is applied here for temperature anomalies instead. The approach was recently used by the authors to study temperature variability and its projected changes in the Southern Hemisphere $(\mathrm{SH})^{28}$. In the $\mathrm{SH}$, the temperature skewness is characterized by a band of positive skewness on the poleward side of the midlatitude storm tracks, and a band of negative skewness on the equatorward side. In the $\mathrm{NH}$, the existence of large continents complicates this picture, and high spatial heterogeneity in skewness is observed rather than a simple dipole structure.

The feature-tracking algorithm is applied separately for the $850 \mathrm{hPa}$ cold and warm temperature anomalies, and the spatial distribution of their mean intensities then constructed (Fig. 3). This allows the temperature variance to be decomposed into the separate contributions from cold (Fig. 3a,e) and warm anomalies (Fig. 3b,f). While the intensity (in absolute value) of both types of anomalies generally maximizes over continents, notable differences are observed, with some 

can be used to estimate the temperature variance and skewness as

$$
\sigma^{2} \approx\left(\frac{1}{2}\left(T_{w}+T_{c}\right)\right)^{2}
$$

and

$$
S \approx \frac{T_{w}-T_{c}}{\frac{1}{2}\left(T_{w}+T_{c}\right)}
$$

91 (see section 2 in the Supplementary Information for the derivation of this approximation), where

regions experiencing stronger cold anomalies and others stronger warm anomalies.

The decomposition into cold and warm temperature anomalies allows us to directly evaluate the distinct contribution of each to the projected regional changes. For example, the projected winter changes in the mean intensity of cold (Fig. 3c) and warm (Fig. 3d) anomalies clearly show that while both types of anomalies are projected to decrease in magnitude, the cold anomalies weaken more. In addition, a limited strengthening of both is found over some regions in central and southern Europe (although less model agreement is found there). In summer, the projected changes in the intensity of both cold and warm anomalies show robust increases over central Europe, with cold anomalies increasing to the northwest and extending towards the British Isles and the Atlantic Ocean, and warm anomalies increasing mainly in the northeastern parts.

Assuming small asymmetry between the cold and warm anomalies, their mean intensities 
while the approximate skewness (2) measures the normalized asymmetry between the cold and the warm anomalies (and equals zero if $T_{c}=T_{w}$ ). The approximate skewness, estimated using the tracking statistics of the mean intensities, recovers well the temperature skewness (Fig. 2b,f) and its projected changes (Fig. 2d,h), albeit with somewhat smaller values.

The dynamical origin of the changes in cold and warm temperature anomalies is demonstrated next for two regional examples, and then generalized using a simple model.

\section{Regional examples}

We first examine a region in east-central North America (black box in Fig. 1-3, panels a-d), for which the ensemble-mean historical temperature PDF is negatively skewed in winter (Fig. 4a, solid line). The tracking results indeed show that the intensities of cold anomalies that pass through this region in the historical simulations (Fig. 4b, blue solid lines) reach larger magnitudes than the warm anomalies (Fig. 4c, red solid lines) (see Methods). The projected temperature variability changes in this region are representative of the changes over most of the $\mathrm{NH}$ during winter, and exhibit a decrease in variance and a positive skewness change (Fig. 4a, dashed line). Consistent with this, both the cold and warm anomalies that cross the region weaken in the projected simulations (blue and red dashed lines in Figs. $4 \mathrm{~b}$ and $4 \mathrm{c}$, respectively), but the cold anomalies weaken substantially more such that there is a positive skewness change. There is also a robust agreement between models regarding the sign of these projected changes (Fig. 4d-g).

A composite analysis of strong cold and warm anomalies that pass through the region (see 
Methods) provides further insight regarding the dynamical origin of these changes. Figs. $4 \mathrm{~h}$ and $4 \mathrm{i}$ show the projected anomalous circulation associated with strong cold and warm events, respectively, overlaid with the projected background temperature change. For strong cold events (Fig. 4h), the anomalous northerly flow entering the region experiences a warmer background temperature to the north, hence the air is advected over a region with reduced meridional temperature gradient (Extended Data Fig. 4), and the cold anomalies weaken. A smaller decrease occurs for the anomalous southerly flow entering the region during the warm events (Fig. 4i), resulting in a smaller reduction of the warm anomalies.

Without considering the skewness changes, one overestimates the risk ratio (calculated as the ratio of the Cumulative Density Functions between historical and projected temperatures) of low temperature extremes (dashed blue line in Fig. 4j), and underestimates the risk ratio of high temperature extremes (dashed red line in Fig. 4k). For example, in this region, the risk ratio of reaching a temperature below $250 \mathrm{~K}$ is doubled (from 0.06 to 0.12 ) (Fig. $4 \mathrm{j}$ ), while the risk ratio of exceeding a temperature of $285 \mathrm{~K}$ is underestimated by about $60 \%$ (from 3.9 to 1.6) (Fig. $4 \mathrm{k}$ ), if skewness changes are neglected. Repeating this analysis for kurtosis shows much smaller changes (Extended Data Fig. 5).

Over central Europe during summer (black box in Fig. 1-3, panels e-h), the ensemble mean historical temperature PDF is positively skewed (Fig. 5a, solid line). Variance increases while skewness slightly decreases in the projected simulations (Figs. 5a-g), although there is greater model spread in the sign of the projected skewness change (Figs. 5g). The projected background 
temperature increase is maximized around southern Europe and the northern Mediterranean region, and the meridional temperature gradient therefore increases over central Europe (Extended Data Fig. 4). Hence, during strong cold events, the northwesterly flow entering the region (Fig. 5h) experiences a stronger background temperature gradient, and the cold anomalies intensify. Similarly, during strong warm events, the anomalous southerly flow entering central Europe (Fig. 5i) experiences a stronger meridional temperature gradient, albeit somewhat smaller, and the warm temperature anomalies therefore also intensify, but to a lesser extent. Note that the increase in the zonal temperature gradient over central Europe and the west of Iberia (Extended Data Fig. 4) also contributes to the intensification of the warm anomalies. Overall, the skewness changes are relatively small and slightly negative when averaged over central Europe (Fig. 5g).

Neglecting the skewness changes nevertheless results in an underestimation of the extreme cold tail (dashed blue line in Fig. 5j) and an overestimation of the extreme warm tail (dashed red line in Fig. 5k). For example, in this region the risk ratio of reaching a temperature below $275 \mathrm{~K}$ is almost halved (from 0.06 to 0.03 ) if one neglects the skewness changes (Fig. 5j), while the risk ratio of exceeding a temperature above $304 \mathrm{~K}$ is overestimated by about $20 \%$ (from 42 to 50 ) (Fig. 5k).

\section{Dynamical origin of temperature changes}

The two regional examples discussed above can be generalized using simple arguments. Given that strong cold and warm temperature anomalies are mostly associated with northerly and southerly 
winds, respectively ${ }^{22}$, we can understand the first-order changes in variance and skewness given the changes in the meridional background temperature gradients as follows. From Taylor's theorem, one can express the cold and warm temperature anomalies arising from horizontal advection as $T_{c}^{\prime}=-\eta_{N} \bar{T}_{N y}$ and $T_{w}^{\prime}=-\eta_{S} \bar{T}_{S y}$, respectively. Here, $\eta_{N}<0$ is the meridional displacement of the cold anomaly (which is negative since it is coming from the north), and $\eta_{S}>0$ is the meridional displacement of the warm anomaly (coming from the south). We further denote $\bar{T}_{N y}$ as the averaged background temperature gradient experienced by the cold anomaly during its movement from the north, and similarly $\bar{T}_{S y}$ for the warm anomaly.

It is clear from the expressions above for $T_{c}^{\prime}$ and $T_{w}^{\prime}$ and (2) for the approximate skewness how a nonzero local temperature skewness can be obtained, $S \approx \frac{\left|\eta_{S} \bar{T}_{S y}\right|-\left|\eta_{N} \bar{T}_{N y}\right|}{\frac{1}{2}\left(\left|\eta_{S} \bar{T}_{S y}\right|+\left|\eta_{N} \bar{T}_{N y}\right|\right)}$, if $\left|\eta_{N} \bar{T}_{N y}\right| \neq$ $\left|\eta_{S} \bar{T}_{S y}\right|$. Moreover, if nonuniform changes in the background temperature gradient occur, both the variance and skewness can change locally. Denoting $\Delta \bar{T}_{N_{y}}$ and $\Delta \bar{T}_{S_{y}}$ as the changes in the meridional background temperature gradient to the north and south of a region, one finds $\Delta T_{c}^{\prime}=$ $-\eta_{N} \Delta \bar{T}_{N_{y}}$ for the cold anomalies, and $\Delta T_{w}^{\prime}=-\eta_{S} \Delta \bar{T}_{S_{y}}$ for the warm anomalies. Here we have assumed for simplicity that $\eta_{N}$ and $\eta_{S}$ remain the same in the future climate, but the meridional displacements can generally change too (although in the regions we have examined, the changes appear to be small, Extended Data Fig. 6). In the limit of small asymmetry, using (1) and (2) for the approximate variance and skewness (respectively) and the expressions above, we find (see section 3 in the Supplementary Information): 


$$
\Delta \sigma^{2} \approx \sigma^{2}\left[\frac{\Delta \bar{T}_{S_{y}}}{\bar{T}_{S_{y}}}+\frac{\Delta \bar{T}_{N y}}{\bar{T}_{N_{y}}}\right],
$$

171

and

$$
\Delta S \approx \frac{\Delta \bar{T}_{S_{y}}}{\bar{T}_{S_{y}}}-\frac{\Delta \bar{T}_{N y}}{\bar{T}_{N_{y}}} .
$$

Hence, depending on the sign and magnitude of the relative temperature gradient changes to the north and to the south, the variance and skewness can either increase or decrease. Note that close to localized temperature gradients (e.g., due to orography or ocean-continent boundaries), zonal gradients also can be significant in influencing the temperature variability ${ }^{33}$. The equations above can be easily generalized to include zonal gradients by calculating the derivatives in the direction of largest gradient, which will have a westerly/easterly component in these regions.

If the gradient changes both oppose the original temperature gradients (i.e., $\frac{\Delta \bar{T}_{N_{y}}}{\bar{T}_{N_{y}}}<0$ and $\left.\frac{\Delta \bar{T}_{S_{y}}}{\bar{T}_{S_{y}}}<0\right)$, as is the case for most of the NH during winter, and for the first region examined above, then (3) predicts a negative variance change. Furthermore, if the relative decrease to the north $\frac{\Delta \bar{T}_{N y}}{\bar{T}_{N y}}$ is larger than the relative decrease to the south $\frac{\Delta \bar{T}_{S_{y}}}{\bar{T}_{S y}}$, then (4) predicts a positive skewness change. The actual changes are captured nicely by the simplified equations for east-central North America during winter, as presented in Figs. 6a and 6b, which show the predicted vs. actual variance and skewness changes, respectively, across the CMIP5 models. For almost all of the models, the sign of the variance change agrees with the background temperature gradient decrease (Fig. 6a). The theory also helps understand some of the model spread, as models that predict a larger background temperature gradient decrease also show a larger decrease in variance. The skewness changes are 
slightly more scattered (Fig. 6b), but the simplified equations generally capture the correct sign of the skewness change and the model spread, with the models that predict a larger relative gradient decrease to the north exhibiting a larger skewness increase than other models.

Following a similar argument, if the gradient changes to the north and south both reinforce the original temperature gradient (i.e., $\frac{\Delta \bar{T}_{N_{y}}}{\bar{T}_{N_{y}}}>0$ and $\frac{\Delta \bar{T}_{S_{y}}}{\bar{T}_{S_{y}}}>0$ ) (as in the second case examined for central Europe during summer), then from (3) the variance change is positive, while from (4) the skewness change will again depend on the magnitude of the relative gradient changes. The latter explains why a large model spread in skewness change is observed for central Europe during summer, including a disagreement regarding the sign of the change (Fig. $5 \mathrm{~g}$ ), as some models predict large relative gradient changes to the north, while others predict large changes to the south (Fig. 6d). The simplified equations capture this well, including the correct sign of the projected skewness change. There is only a weak correlation between the gradient and the variance increase over central Europe during summer (Fig. 6c). The sign of the change is captured correctly by the simplified equations, but it is clear that the meridional background temperature increase is not the only factor controlling the variance increase. This is probably related to the fact that zonal gradients are also important for this region during summer (Extended Data Fig. 4h), and also because land-surface processes, such as interaction with soil-moisture, become more important during summer ${ }^{1,5,34}$. Note that for both winter and summer, the weaker correlation found in Fig. $6 \mathrm{~b}$ and 6c compared to Fig. 6d and 6a, respectively, may also reflect the smaller model spread in these cases (i.e. there is less spread across models to be explained). 
Finally, the expressions for the variance and skewness given in (1) and (2) can be used to estimate the intensities of cold and warm temperature anomalies. It is easy to show that (see section 4 in the Supplementary Information):

$$
T_{c} \approx \sigma\left(1-\frac{S}{2}\right)
$$

and

$$
T_{w} \approx \sigma\left(1+\frac{S}{2}\right)
$$

If the actual variance and skewness are used in (5) and (6), then the amplitude of the cold and warm temperature anomalies can be estimated directly and compared with the tracking results. The projected changes in these estimated intensities are shown in Figs. 6e-h, which recover well the intensity changes found using the Lagrangian approach (Fig. 3). For example, these expressions correctly capture the stronger reduction in the intensity of cold anomalies in most of the NH during winter, and also correctly capture the increase of both types of anomalies over central Europe during summer.

This study has examined the variability of lower tropospheric $(850 \mathrm{hPa})$ temperature in order to better isolate the role of large-scale horizontal advection. A basic mechanism for temperature skewness generation by linear advection of nonuniform background temperature gradients is presented, and simple expressions are derived to relate variance and skewness changes to background temperature gradient changes, which describe well the projected model changes.

However, it is well known that processes associated with snow or ice melting and land 
cover also influence the surface temperature variability during winter ${ }^{18,35-38}$. The relevance of our $850 \mathrm{hPa}$ level findings for surface temperature can be examined by inspecting the near-surface (T2m) winter temperature response (Extended Data Fig. 7). Overall, the winter mean and variance changes are similar between the two levels, but there are quite significant differences between the $850 \mathrm{hPa}$ level and the surface temperature skewness changes (compare Extended Data Fig. 7c,f with Fig. 2a,c). The projected winter skewness changes are similar in the midlatitudes, but a negative (rather than positive) skewness change is projected poleward of the $0^{\circ} \mathrm{C}$ temperature line (Extended Data Fig. 7c,f). The negative skewness change was proposed to be a direct result of snow and sea ice melting ${ }^{18}$. However, the origin of the positive midlatitude skewness change had previously been unexplained. During summer, other processes such as soil-moisture interactions are known to be extremely important for surface temperature variability and extremes ${ }^{34,35,39-42}$. It has also been shown that the correlation between atmospheric circulation and surface temperature variability is weaker in summer compared to winter ${ }^{43}$. However, the overall structure of the projected $850 \mathrm{hPa}$ summer mean, variance, and skewness changes still resemble well the T2m response (Extended Data Fig. 8) (except in the Arctic). This again points towards a purely dynamical mechanism shaping the temperature variability changes, which does not involve the boundary layer.

The current study therefore provides an important element in understanding midlatitude surface temperature changes, by explaining and quantifying the fundamental role of advection and warming patterns in shaping the variance and skewness changes. These are more cleanly revealed by analyzing the $850 \mathrm{hPa}$ level, where the dynamical contribution can be isolated. Examining the 
relative importance of atmospheric circulation and regional land-surface feedbacks in shaping the surface temperature variability response to climate change is left for further study.

\section{Methods}

\section{Data}

In this study we use the 6-hourly $850 \mathrm{hPa}$ temperature field from 26 CMIP5 models (see model list in Table S1 in the Supplementary Information). All models are forced by the representative concentration pathway 8.5 (RCP8.5) emissions scenario, and the r1i1p1 ensemble member is used ${ }^{44}$. The data covers a period of 19 years in the historical runs (1981-1999), which include both the observed anthropogenic and natural atmospheric forcings, and 19 years in the projected runs (2081-2099), in which the radiative forcing increases by about $8.5 \mathrm{~W} \mathrm{~m}^{-2}$ by year 2100 . For each model, the background climatology is defined for every 6-hourly time period as its average over the 19 years, in order to remove both the diurnal and the seasonal cycle. Perturbations are then defined as deviations from the 6-hourly climatology (for the historical and projected simulations separately). The variance and skewness are calculated first for each model separately, and then averaged together to produce the ensemble means. We concentrate on the NH during both the winter (DJF) and summer (JJA) seasons.

To examine the accuracy of the historical CMIP5 data in reproducing the observed temperature variability, we also analyze ERA-I reanalysis data ${ }^{45}$ (Extended Data Fig. 2 and Extended Data Fig. 3). We use the 6-hourly $850 \mathrm{hPa}$ temperature field from the ECMWF ERA-I reanaly- 
sis dataset, covering the years 1980-2014, where the background climatology is defined for every 6-hourly time period as its average over the 35 years.

\section{Tracking algorithm}

The current study employs the objective spherical feature-tracking algorithm TRACK ${ }^{46,47}$, which is typically used for cyclone tracking, but is modified here to track temperature anomalies instead. We track the $850 \mathrm{hPa}$ temperature perturbations by subtracting the background state, defined as the 6-hourly climatology (compared with the spatial filtering of the large scale background flow that is usually applied for cyclones). The 6-hourly temperature anomaly field is then reduced to a T42 grid to smooth the data and reduce noise. The positive and negative temperature anomalies are identified as the maxima or minima of the anomaly field, respectively, that exceed a threshold of $0.5 \mathrm{~K}$. The positive and negative centers are then tracked separately every 6 hours. This tracking is performed directly on the sphere, and is achieved by first initializing the maxima or minima into a set of tracks using a nearest neighbour method, and then refining these by performing a constrained minimization of a cost function for track smoothness (formulated in spherical coordinates) ${ }^{47}$. Only features that last for more than two days are retained for the statistical calculations, which includes semi-stationary features as well as the more mobile systems (so that more slowly propagating perturbations like heat waves can be identified too). The spatial statistics of the tracked anomalies are then obtained using adaptive locally defined spherical kernel estimators, which are a form of distance weighted statistical estimator ${ }^{48}$. For example, the mean intensity at a certain grid point is estimated from the intensity of adjacent track points using a decay function (the local spherical kernel estimator), which depends on the distance between the track point and the gridpoint. The 
kernel bandwidth, which controls the statistic smoothness, is adapted according to the data density. This approach has the benefit of computing the statistics directly on the sphere which prevents the introduction of biases that often occur for grid box methods. The spatial statistics are computed for each model separately, and then averaged together.

\section{Regional composites}

The regional composites of the anomalous velocity associated with strong cold and warm temperature anomalies are constructed using the tracking results of the $850 \mathrm{hPa}$ temperature anomalies. For each model, we first find the intensity of all the cold and warm anomalies that passed through the region, keeping only the maximum value reached inside the region box. We then find, for the cold and warm anomalies separately, the $75^{\text {th }}$ percentile thresholds. The composites of strong cold and warm anomalies are then constructed by averaging only over features whose maximum intensity exceeds the $75^{\text {th }}$ percentile (similar results are obtained when other percentile thresholds are used instead). This is performed for each model separately, and the composites are then averaged together, centered around the middle of the region box, for positive and negative anomalies separately.

The meridional temperature gradients $T_{N_{y}}$ and $T_{S_{y}}$ used to estimate the variance and skewness changes given by (3) and (4) (and shown in Figs. 6a-d) are calculated as the linear gradients over four grid points to the north and to the south of the centers of each region box, respectively. They are calculated for the seasonally averaged background temperature and hence are time-independent. 


\section{Statistical data analysis}

The Eulerian PDFs (presented in Figs. 4a and 5a) are calculated by accumulating all the temperature anomalies (from all models) in a given region, and then adding the multi-model mean temperature for the region. These are compared to the PDFs of intensity of anomalies from the tracking (presented in Figs. 4b,c and 5b,c), calculated by accumulating all the positive and negative features that pass through each region. The PDFs are obtained using a kernel fitting, and the shading denotes the $95 \%$ confidence interval, calculated using a two-tailed t-distribution with 26 degrees of freedom $\left(t_{s} \approx 2.06\right)$ and multiplying by the standard error of the mean model spread (for each value of the PDF).

\section{Data availability}

The datasets analyzed in the current study were obtained from the World Data Center for Climate (WDCC) repository, available at http://cera-www.dkrz.de/WDCC/ui/.

\section{Code availability}

The feature-tracking algorithm used in this study is available for download at http://www.nercessc.ac.uk/ kih/TRACK/Track.html, by contacting Kevin Hodges (k.i.hodges@ reading.ac.uk).

1. Schär, C. et al. The role of increasing temperature variability in European summer. Nature 427, 332-336 (2004).

2. Newman, W. I., Malamud, B. D. \& Turcotte, D. L. Statistical properties of record-breaking 
temperatures. Phys. Rev. E 82, 066111 (2010).

3. Schneider, T., Bischoff, T. \& Płotka, H. Physics of changes in synoptic midlatitude temperature variability. J. Climate 28, 2312-2331 (2015).

4. Petoukhov, V., Eliseev, A. V., Klein, R. \& Oesterle, H. On statistics of the free-troposphere synoptic component: an evaluation of skewnesses and mixed third-order moments contribution to the synoptic-scale dynamics and fluxes of heat and humidity. Tellus A: Dynamic Meteorology and Oceanography 60, 11-31 (2008).

5. Fischer, E. M. \& Schär, C. Future changes in daily summer temperature variability: Driving processes and role for temperature extremes. Clim. Dyn. 33, 917-935 (2009).

6. Ruff, T. W. \& Neelin, J. D. Long tails in regional surface temperature probability distributions with implications for extremes under global warming. Geophys. Res. Lett. 39, 1-6 (2012).

7. Perron, M. \& Sura, P. Climatology of non-Gaussian atmospheric statistics. J. Climate 26, 1063-1083 (2013).

8. Kodra, E. \& Ganguly, A. R. Asymmetry of projected increases in extreme temperature distributions. Sci. Rep. 4, 5884 (2014).

9. Sardeshmukh, P. D., Compo, G. P. \& Penland, C. Need for caution in interpreting extreme weather statistics. J. Climate 28, 9166-9187 (2015). 
10. Garfinkel, C. I. \& Harnik, N. The non-Gaussianity and spatial asymmetry of temperature extremes relative to the storm track: The role of horizontal advection. J. Climate 30, 445-464 (2017).

11. Loikith, P. C. \& Neelin, J. D. Non-Gaussian cold-side temperature distribution tails and associated synoptic meteorology. J. Climate 32, 8399-8414 (2019).

12. Linz, M., Chen, G., Zhang, B. \& Zhang, P. A framework for understanding how dynamics shape temperature distributions. Geophys. Res. Lett. 47, e2019GL085684 (2020).

13. Loikith, P. C. \& Broccoli, A. J. Characteristics of observed atmospheric circulation patterns associated with temperature extremes over North America. J. Climate 25, 7266-7281 (2012).

14. Donat, M. G. \& Alexander, L. V. The shifting probability distribution of global daytime and night-time temperatures. Geophys. Res. Lett. 39, L14707 (2012).

15. Volodin, E. M. \& Yurova, A. Y. Summer temperature standard deviation, skewness and strong positive temperature anomalies in the present day climate and under global warming conditions. Clim. Dyn. 40, 1387-1398 (2013).

16. Huybers, P., McKinnon, K. A., Rhines, A. \& Tingley, M. U.S. daily temperatures: The meaning of extremes in the context of nonnormality. J. Climate 27, 7368-7384 (2014).

17. Diao, Y., Xie, S.-P. \& Luo, D. Asymmetry of winter European surface air temperature extremes and the North Atlantic Oscillation. J. Climate 28, 517-530 (2015). 
18. Gao, Y., Leung, L. R., Lu, J. \& Masato, G. Persistent cold air outbreaks over North America in a warming climate. Environ. Res. Lett. 10, 044001 (2015).

19. Loikith, P. C. et al. Surface temperature probability distributions in the NARCCAP hindcast experiment: evaluation methodology, metrics, and results. J. Climate 28, 978-997 (2015).

20. Bindoff, N. L. et al. Detection and attribution of climate change: from global to regional. Climate Change 2013: The Physical Science Basis. Contribution of Working Group I to the Fifth Assessment Report of the Intergovernmental Panel on Climate Change (2013).

21. Field, C. et al. (eds.) IPCC, 2012: Managing the Risks of Extreme Events and Disasters to Advance Climate Change Adaptation. A Special Report of Working Groups I and II of the Intergovernmental Panel on Climate Change (Cambridge University Press, Cambridge, UK, and New York, NY, USA, 2012).

22. Screen, J. A. Arctic amplification decreases temperature variance in northern mid- to highlatitudes. Nat. Clim. Change. 4, 577-582 (2014).

23. Parey, S., Hoang, T. T. H. \& Dacunha-Castelle, D. The importance of mean and variance in predicting changes in temperature extremes. J. Geophys. Res. Atmos. 118, 8285-8296 (2013).

24. Holmes, C. R., Woollings, T., Hawkins, E. \& de Vries, H. Robust future changes in temperature variability under greenhouse gas forcing and the relationship with thermal advection. $J$. Climate 29, 2221-2236 (2016).

25. Ballester, J., Giorgi, F. \& Rodó, X. Changes in European temperature extremes can be predicted from changes in PDF central statistics. Climatic Change 98, 277-284 (2009). 
26. McKinnon, K. A., Rhines, A., Tingley, M. P. \& Huybers, P. The changing shape of Northern Hemisphere summer temperature distributions. J. Geophys. Res. Atmos. 121, 8849-8868 (2016).

27. Lewis, S. C. \& King, A. D. Evolution of mean, variance and extremes in 21 st century temperatures. Weather and Climate Extremes 15, 1-10 (2017).

28. Tamarin-Brodsky, T., Hodges, K., Hoskins, B. J. \& Shepherd, T. G. A dynamical perspective on atmospheric temperature variability and its response to climate change. J. Climate 32, 1707-1724 (2019).

29. Linz, M., Chen, G. \& Hu, Z. Large-scale atmospheric control on non-Gaussian tails of midlatitude temperature distributions. Geophys. Res. Lett. 45, 9141-9149 (2018).

30. Stocker, T. et al. Climate Change 2013 - The Physical Science Basis. Contribution of Working Group I to the Fifth Assessment Report of the Intergovernmental Panel on Climate Change (Cambridge University Press, Cambridge, UK, and New York, USA, 2014).

31. Fischer, E. M., Rajczak, J. \& Schär, C. Changes in European summer temperature variability revisited. Geophys. Res. Lett. 39, L19702 (2012).

32. Hoskins, B. \& Hodges, K. New perspectives on the Northern Hemisphere winter storm tracks. J. Atmos. Sci. 59, 1041-1061 (2002).

33. Lutsko, N. J., Baldwin, J. W. \& Cronin, T. W. The impact of large-scale orography on northern hemisphere winter synoptic temperature variability. J. Climate 32, 5799-5814 (2019). 
34. Seneviratne, S. I., Lüthi, D., Litschi, M. \& Schär, C. Land-atmosphere coupling and climate change in Europe. Nature 443, 205-209 (2006).

35. Gregory, J. M. \& Mitchell, J. F. Simulation of daily variability of surface temperature and precipitation over Europe in the current and 2xCO2 climates using the UKMO climate model. Q. J. R. Meteorol. Soc. 121, 1451-1476 (1995).

36. Cohen, J. \& Entekhabi, D. The influence of snow cover on northern hemisphere climate variability. Atmosphere - Ocean 39, 35-53 (2001).

37. Findell, K. L. et al. The impact of anthropogenic land use and land cover change on regional climate extremes. Nat. Commun. 8, 989 (2017).

38. Diro, G. T., Sushama, L. \& Huziy, O. Snow-atmosphere coupling and its impact on temperature variability and extremes over North America. Climate Dynamics 50, 2993-3007 (2018).

39. Lenderink, G., Van Ulden, A., Van Den Hurk, B. \& Van Meijgaard, E. Summertime interannual temperature variability in an ensemble of regional model simulations: Analysis of the surface energy budget. Climatic Change 81, 233-247 (2007).

40. Fischer, E. M., Lawrence, D. M. \& Sanderson, B. M. Quantifying uncertainties in projections of extremes-a perturbed land surface parameter experiment. Climate Dynamics 37, 1381-1398 (2011).

41. Berg, A. et al. Impact of soil moisture atmosphere interactions on surface temperature distribution. J. Climate 27, 7976-7993 (2014). 
42. Douville, H., Colin, J., Krug, E., Cattiaux, J. \& Thao, S. Midlatitude daily summer temperatures reshaped by soil moisture under climate change. Geophys. Res. Lett. 43, 812-818 (2016).

43. Vautard, R. \& Yiou, P. Control of recent European surface climate change by atmospheric flow. Geophys. Res. Lett. 36, 6-11 (2009).

44. Taylor, K., Stouffer, R. \& Meehl, G. An overview of CMIP5 and the experiment design. Bull. Amer. Meteor. Soc. 93, 485-498 (2012).

45. Dee, D. P. et al. The ERA-Interim reanalysis: configuration and performance of the data assimilation system. Q. J. R. Meteorol. Soc. 137, 553-597 (2011).

46. Hodges, K. I. Feature tracking on the unit sphere. Mon. Weather Rev. 123, 3458-3465 (1995).

47. Hodges, K. I. Adaptive constraints for feature tracking. Mon. Weather Rev. 127, 1362-1373 (1999).

48. Hodges, K. I. Spherical nonparametric estimators applied to the UGAMP model integration for AMIP. Mon. Weather Rev. 124, 2914-2932 (1996).

Acknowledgements This research has been supported by the James S. McDonnell Foundation for complex systems, and by the European Research Council Advanced Grant (ACRCC) "Understanding the atmospheric circulation response to climate change”, project 339390. The data were obtained from the World Data Center for Climate (WDCC). We acknowledge the World Climate Research Programme's Working Group on Coupled Modelling, which is responsible for CMIP, and we thank the climate modeling groups 
(listed in Table S1 of the SI) for producing and making available their model output. For CMIP the U.S. Department of Energy's Program for Climate Model Diagnosis and Intercomparison provides coordinating support and led development of software infrastructure in partnership with the Global Organization for Earth System Science Portals.

supplementary information Extended Data and Supplementary Information accompany this paper.

Author Contributions T.T.B., K.H., B.J.H. and T.G.S. designed the study and wrote the paper; T.T.B performed the data analyses.

Competing Interests The authors declare that they have no competing financial interests.

Correspondence Correspondence and requests for materials should be addressed to T. Tamarin-Brodsky (email: t.tamarin@reading.ac.uk). 

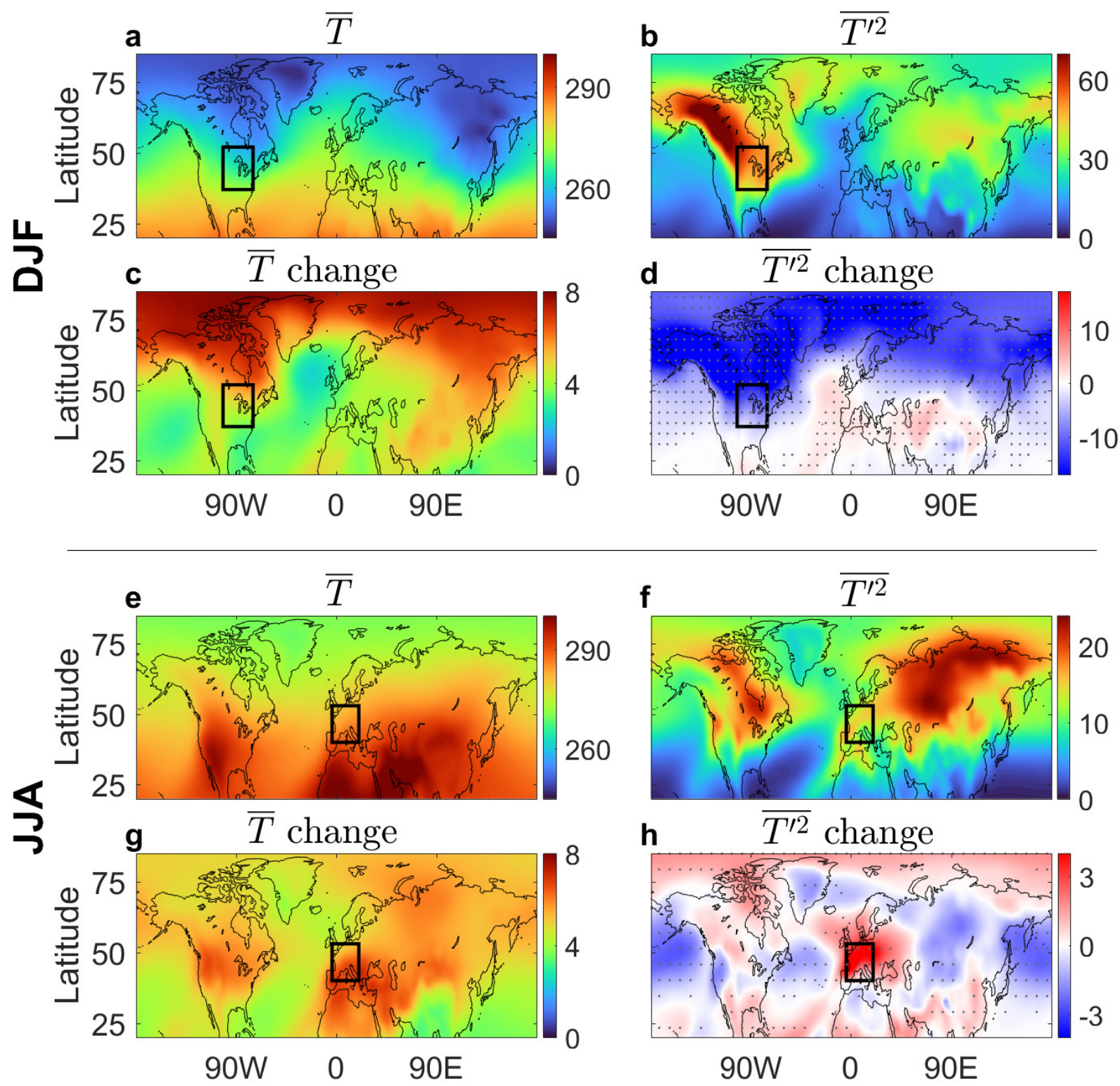

Figure 1: The historical (1981-1999) ensemble-mean climatological temperature and variance and their projected changes (2081-2099 minus historical), based on 26 CMIP5 RCP8.5 ensemble members. The $850 \mathrm{hPa}(\mathrm{a})$ mean temperature $(\mathrm{K})$ and (b) temperature variance $\left(\mathrm{K}^{2}\right)$ during winter (December-January, DJF), and the corresponding projected changes in (c) and (d), respectively. Panels (e)-(h) show the same but for the summer period (June-August, JJA). Regions where more than $70 \%$ of the models agree on the sign of the variance changes are stippled. 

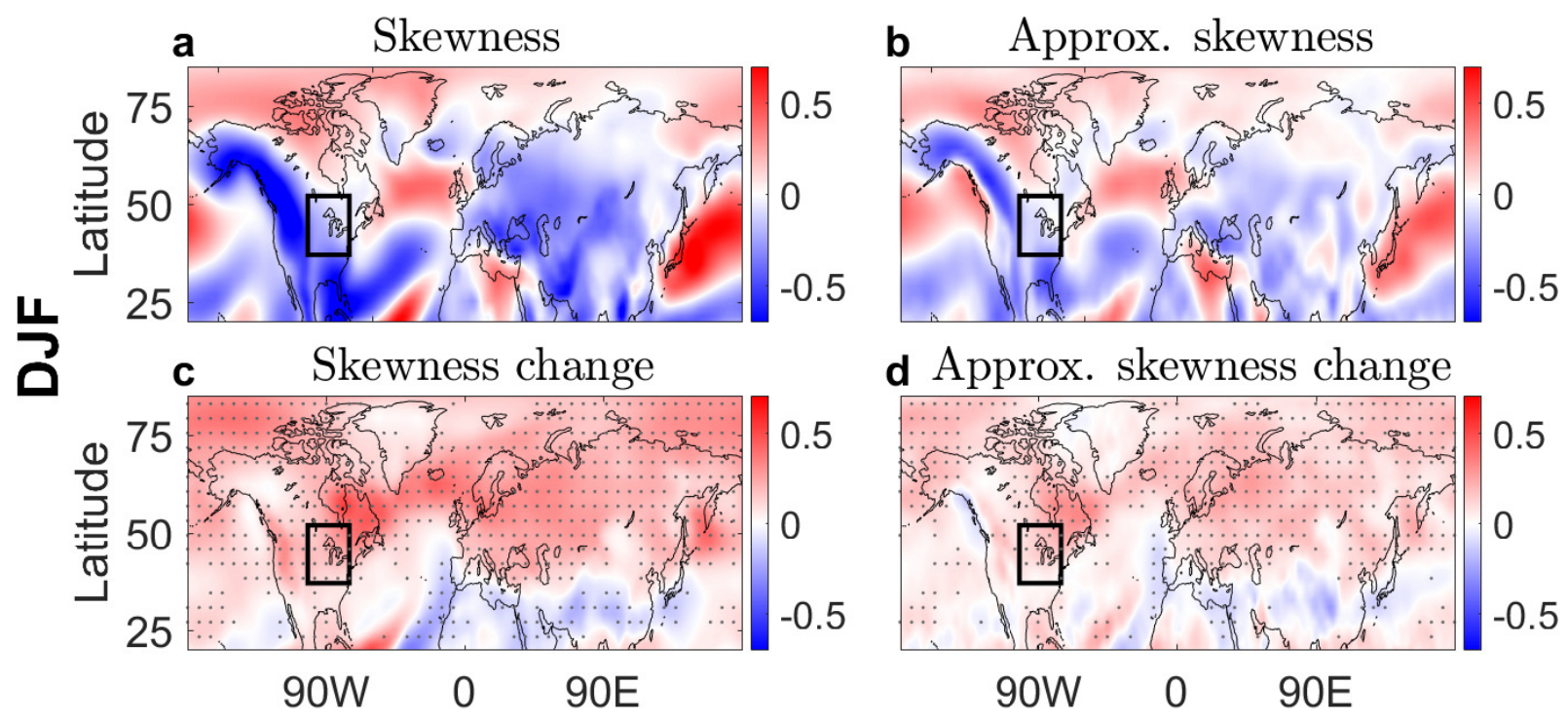

d Approx. skewness change
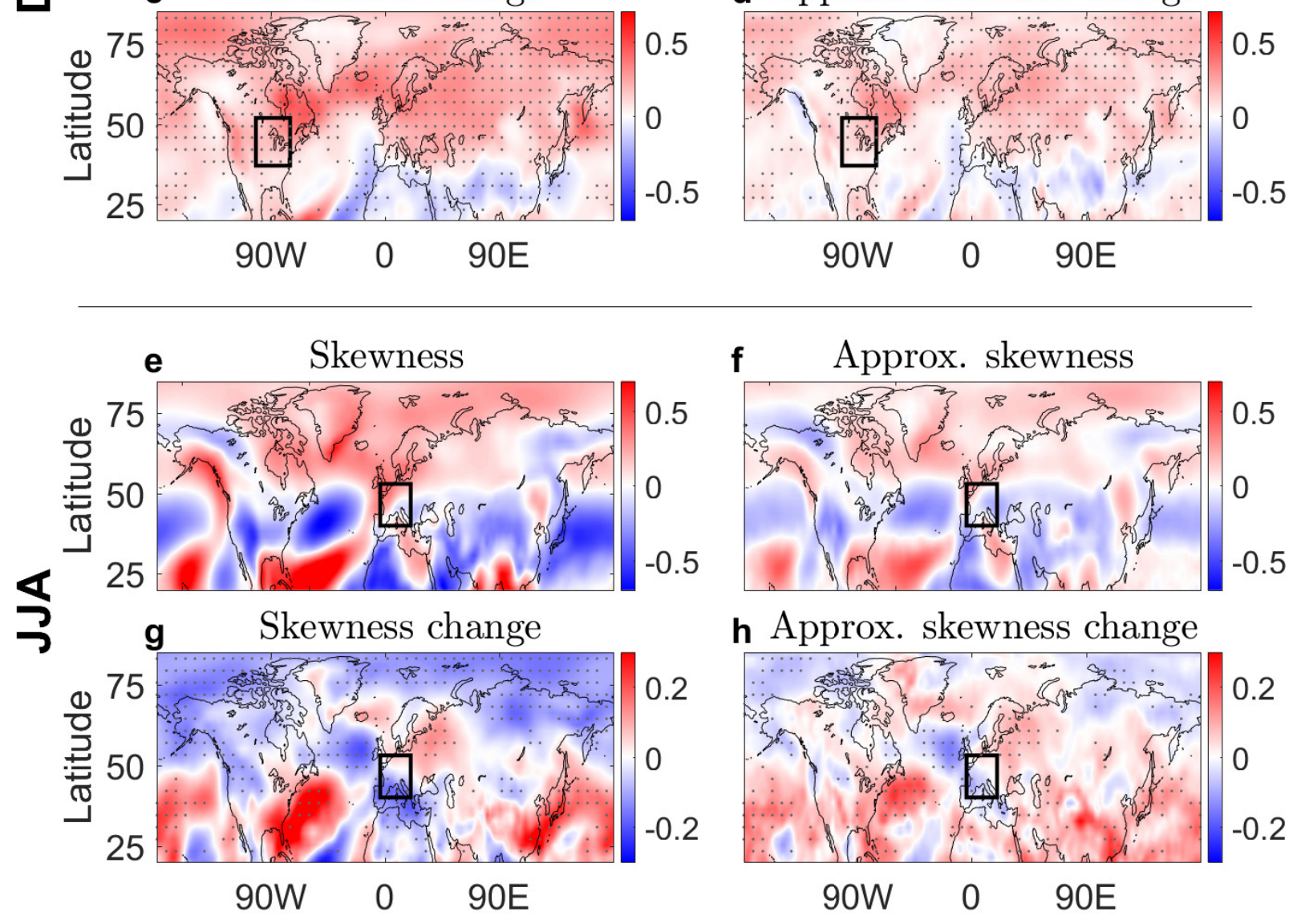

h Approx. skewness change

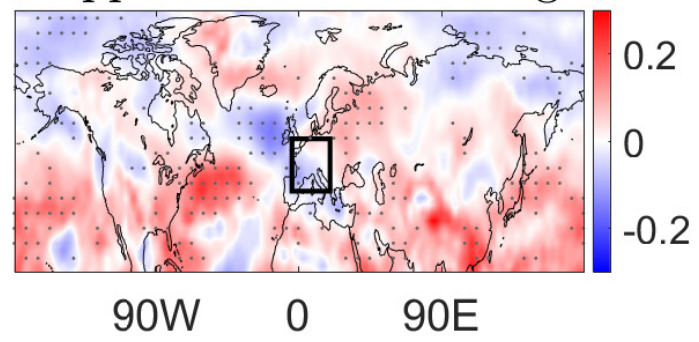

Figure 2: The historical (1981-1999) ensemble-mean temperature skewness and its projected changes (2081-2099 minus historical). The $850 \mathrm{hPa}$ winter (DJF) (a) temperature skewness and (b) approximate temperature skewness, $S \approx \frac{T_{w}-T_{c}}{\frac{1}{2}\left(T_{w}+T_{c}\right)}$ (see Supplementary Information), where $T_{c}$ and $T_{w}$ denote the mean intensity (in absolute value) of the cold and warm temperature anomalies, respectively, produced from the tracking statistics (see Methods and Fig. 3). The corresponding projected changes are shown in (c) and (d), respectively. Panels (e)-(h) show the same but for the summer period (JJA). Regions where more 26 han $70 \%$ of the models agree on the sign of the changes are stippled. 

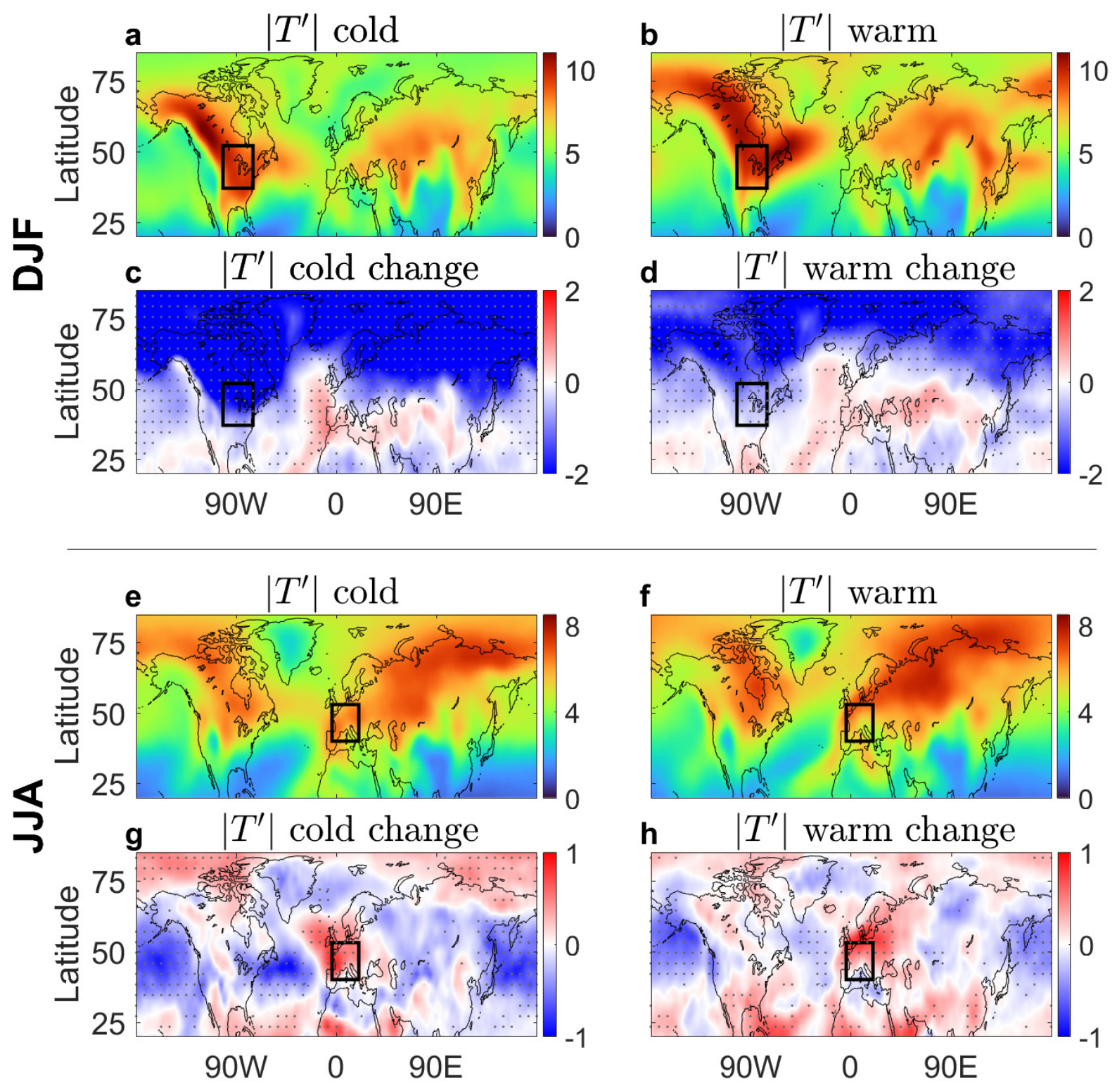

Figure 3: The historical (1981-1999) ensemble-mean intensities of cold and warm anomalies produced from the temperature tracking statistics, and their projected changes (2081-2099 minus historical). The mean intensity of the $850 \mathrm{hPa}$ (a) cold and (b) warm temperature anomalies during winter (DJF), and their corresponding projected changes in (c) and (d), respectively. Panels (e)-(h) show the same but for the summer period (JJA). Regions where more than $70 \%$ of the models agree on the sign of the changes are stippled. 

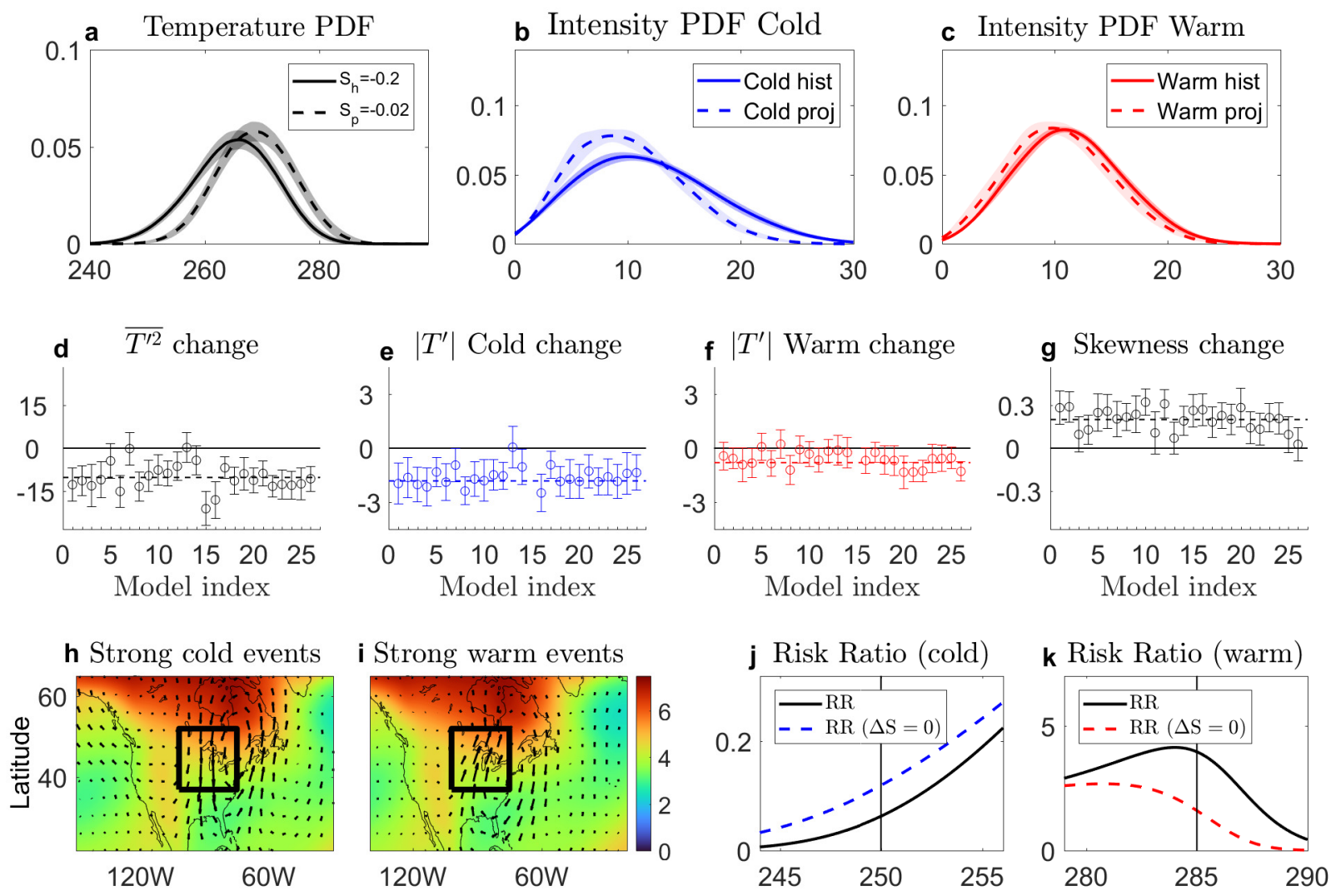

Figure 4: The $850 \mathrm{hPa}$ temperature variability changes in east-central North America during DJF. PDF of (a) temperature (K), and intensity of (b) cold and (c) warm temperature anomalies (K) from the tracking, for the historical (solid lines) and projected (dashed lines) simulations $\left(\mathrm{S}_{\mathrm{h}}\right.$ and $\mathrm{S}_{\mathrm{p}}$ in the legend of (a) denote the corresponding skewness of the PDF). The model spread of the regionaveraged (d) temperature variance $\left(\mathrm{K}^{2}\right)$, (e) intensity of cold and (f) warm temperature anomalies (K) from the tracking statistics, and (g) temperature skewness, where each dot corresponds to a model in accordance with the list in Table S1. Dashed horizontal lines show the ensemble mean averages, and the errorbars denote the $95 \%$ confidence interval from the yearly values for each model. Composites of the anomalous circulation (arrows) in the projected simulations associated with strong (h) cold and (i) warm anomalies that crossed the region (see Methods), and the projected background temperature increase (shadirgs). Black box denotes the region. The risk ratio of the (j) cold and (k) warm tails, with (solid black line) or without (dashed lines) the projected skewness change. 

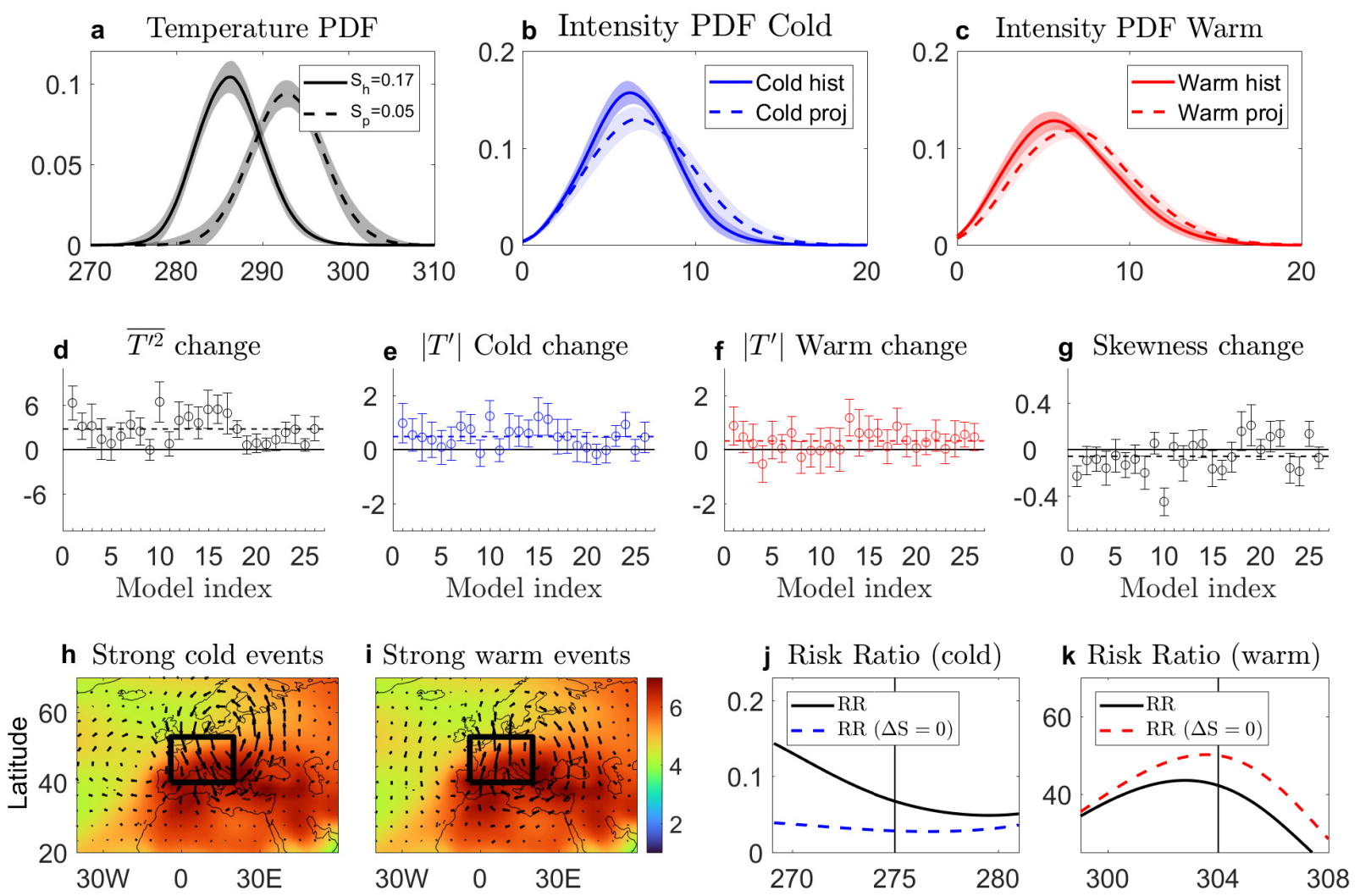

Figure 5: As in Fig. 4 but for central Europe during summer (JJA). 

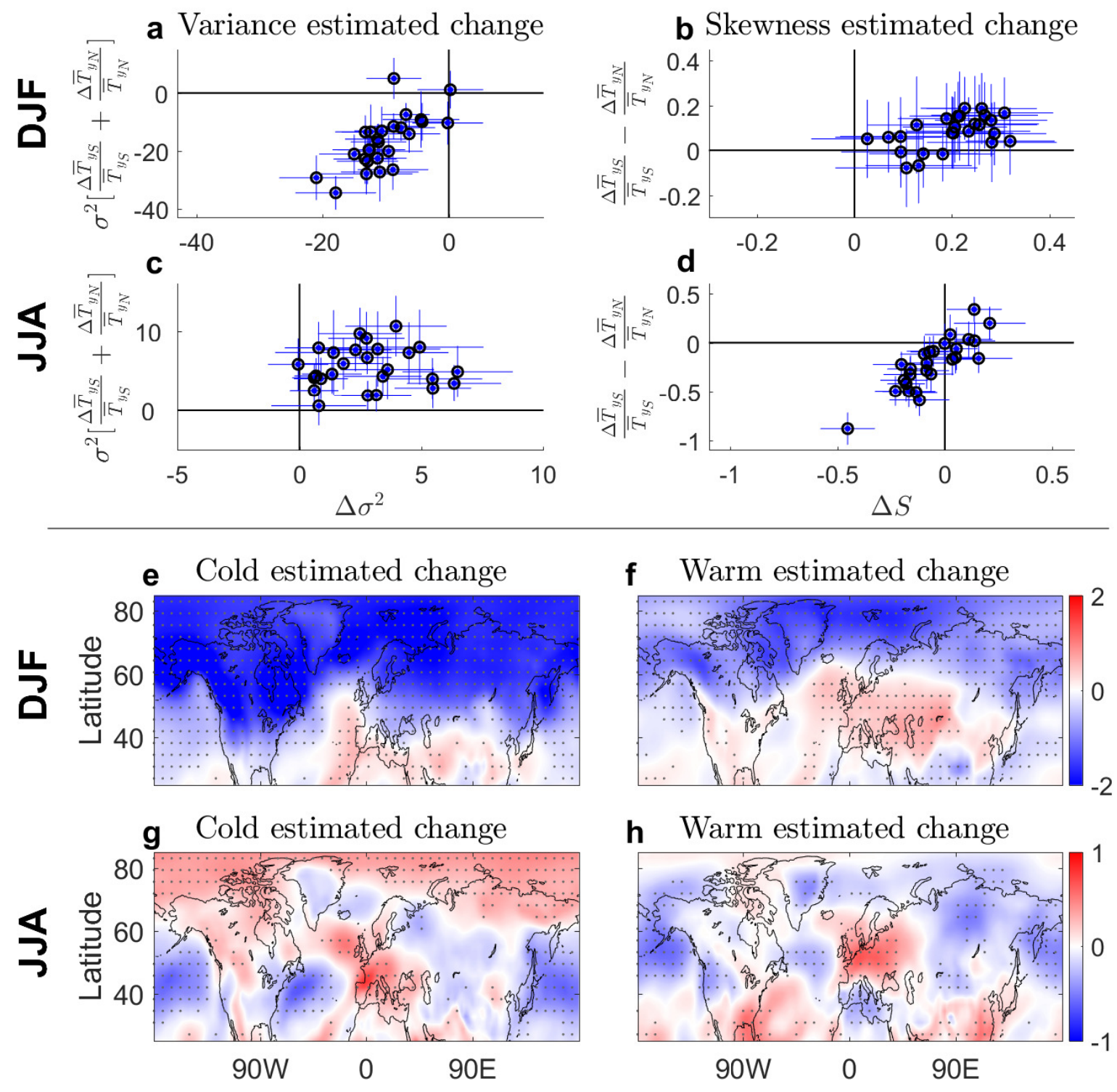


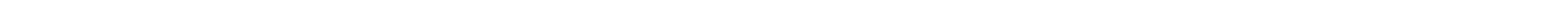



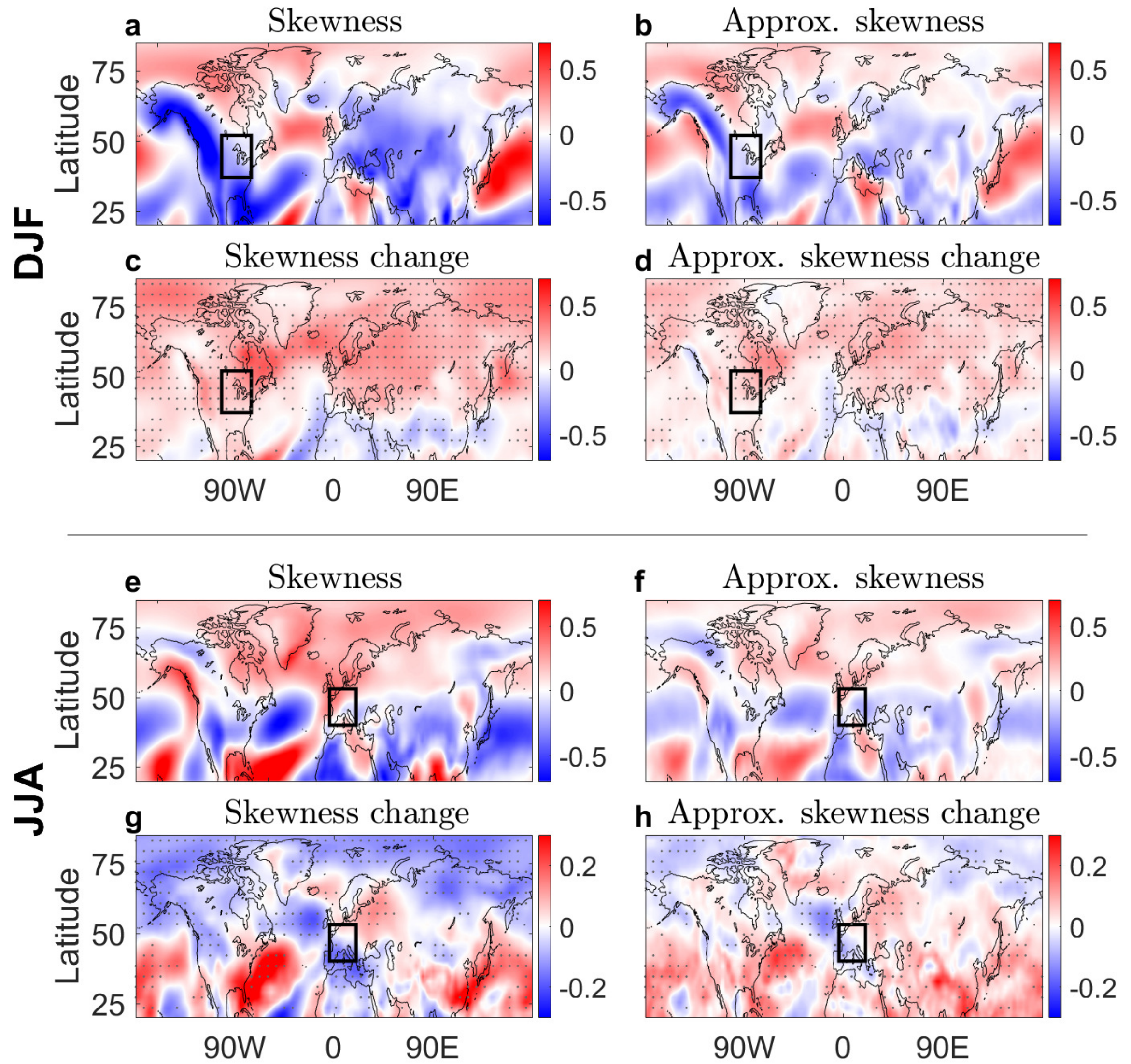

h Approx. skewness change

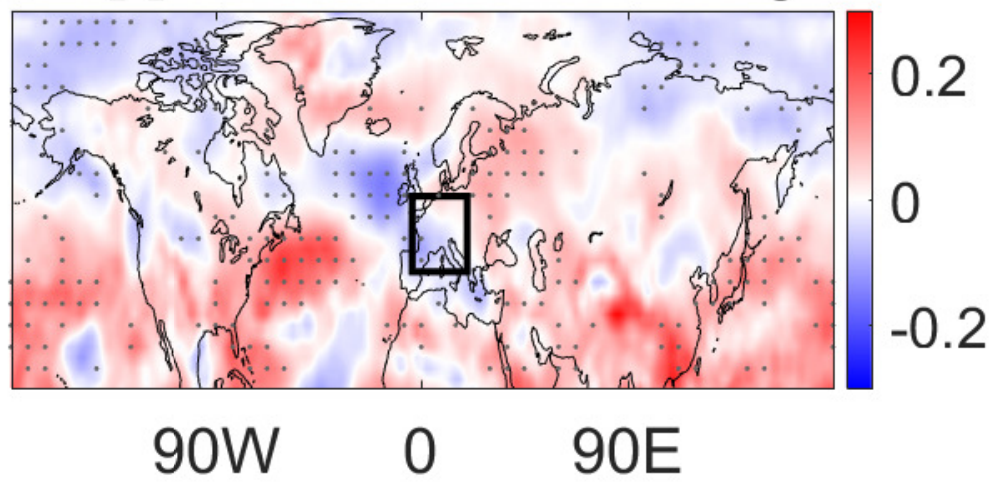




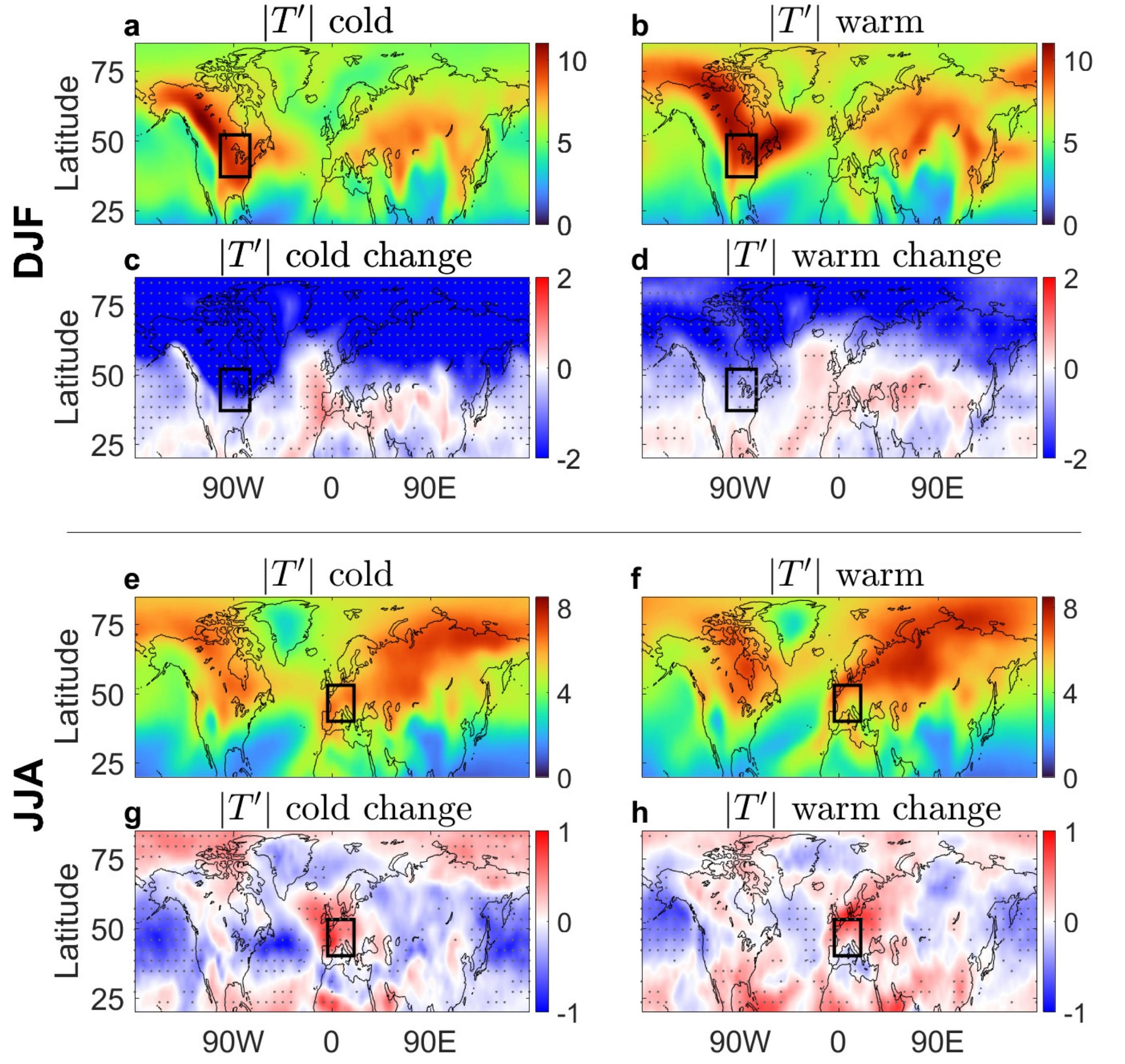



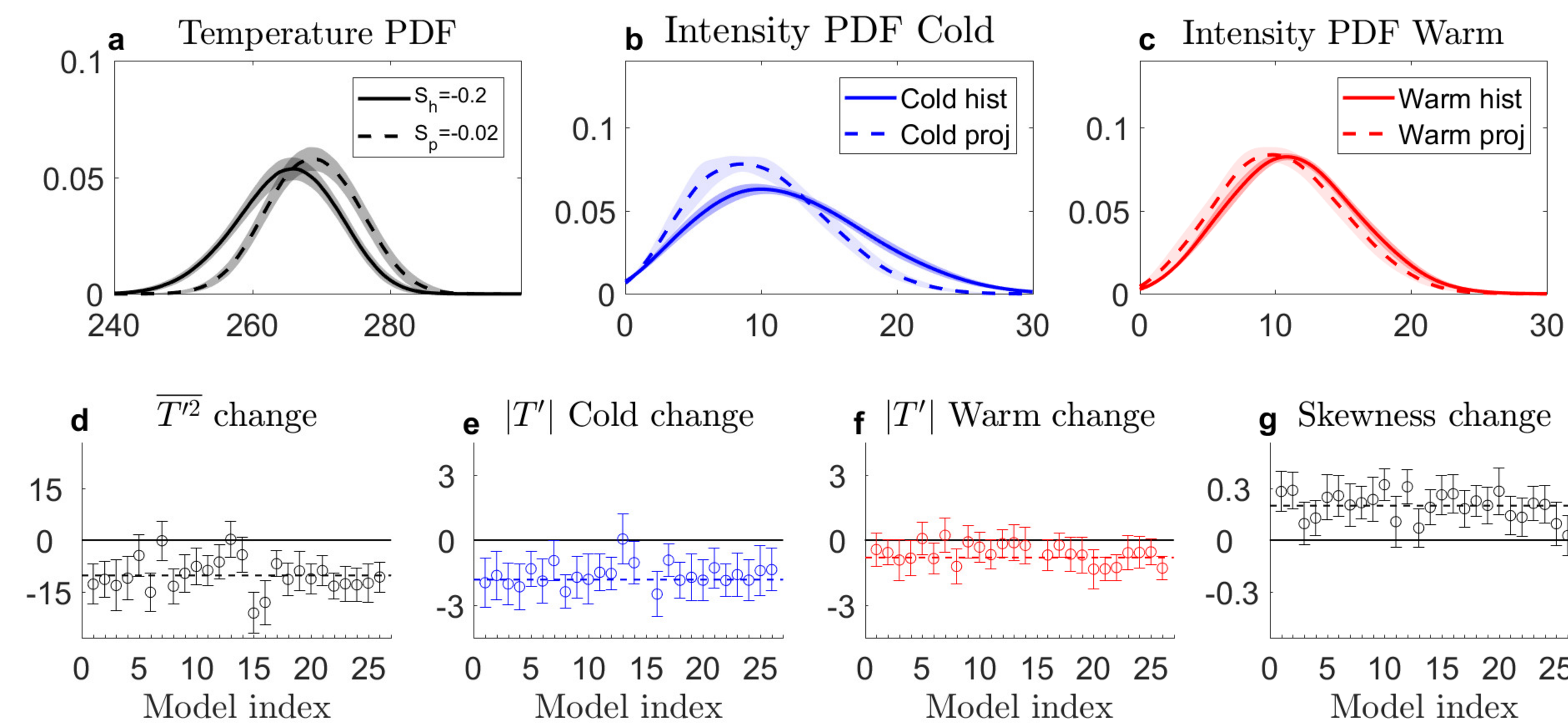

g Skewness change

h Strong cold events

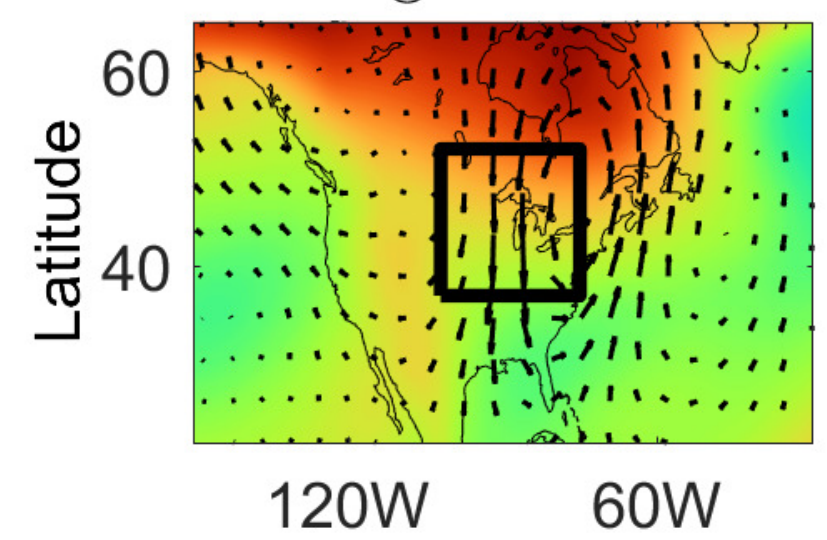

i Strong warm events

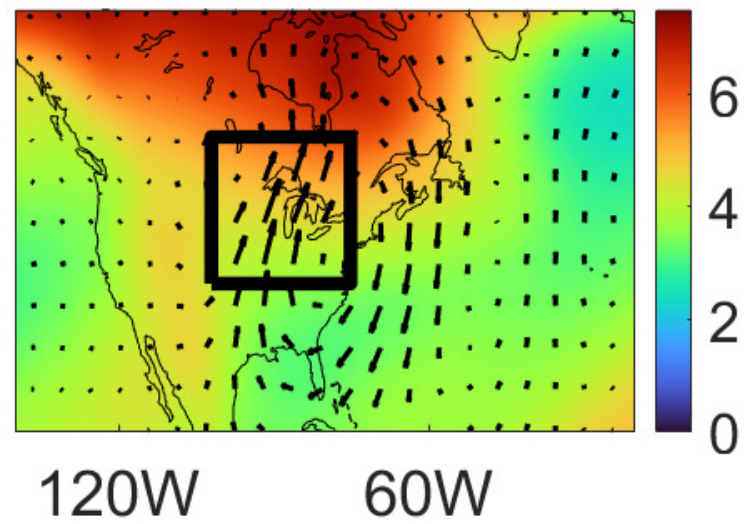

j Risk Ratio (cold)

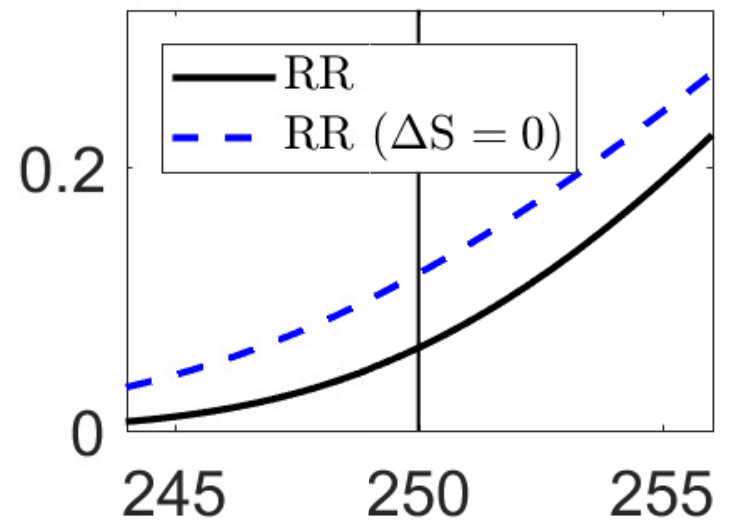

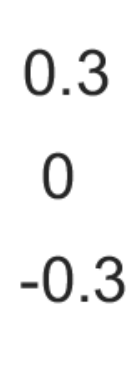

$\begin{array}{llllll}0 & 5 & 10 & 15 & 20 & 25\end{array}$ Model index

k Risk Ratio (warm)

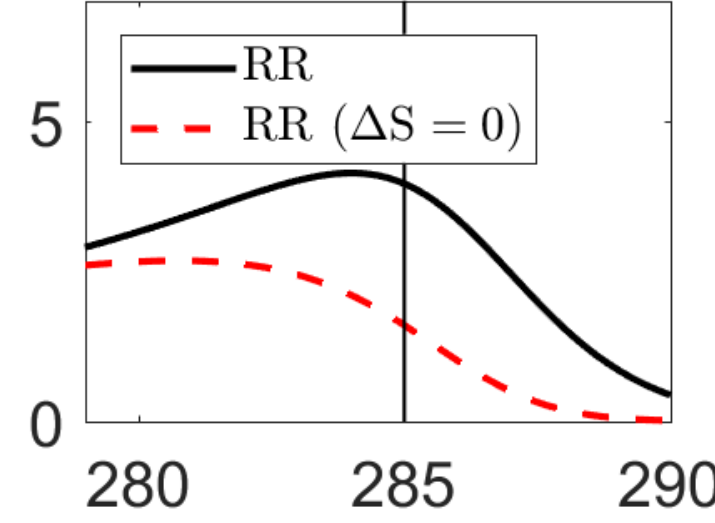



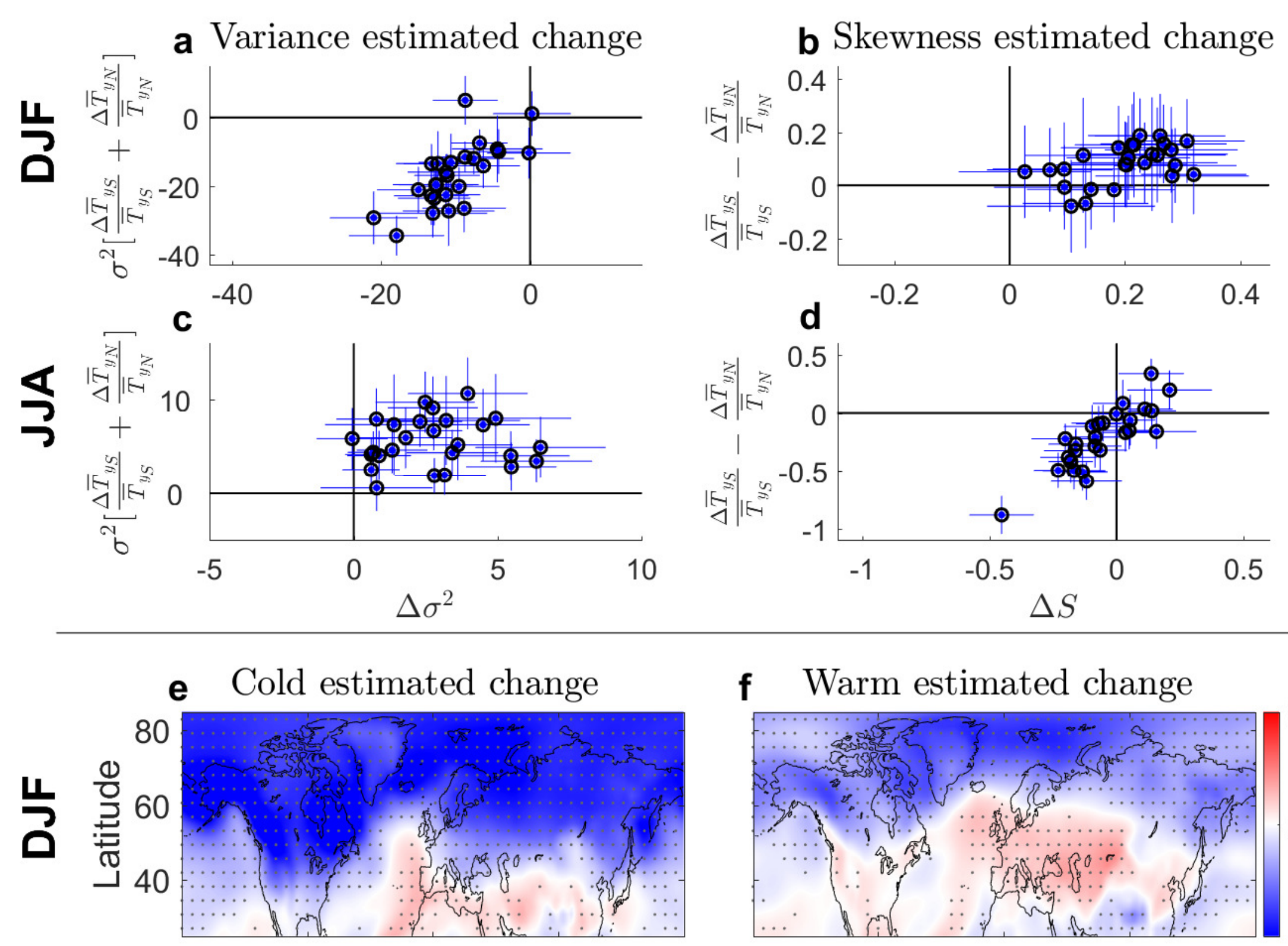

f Warm estimated change
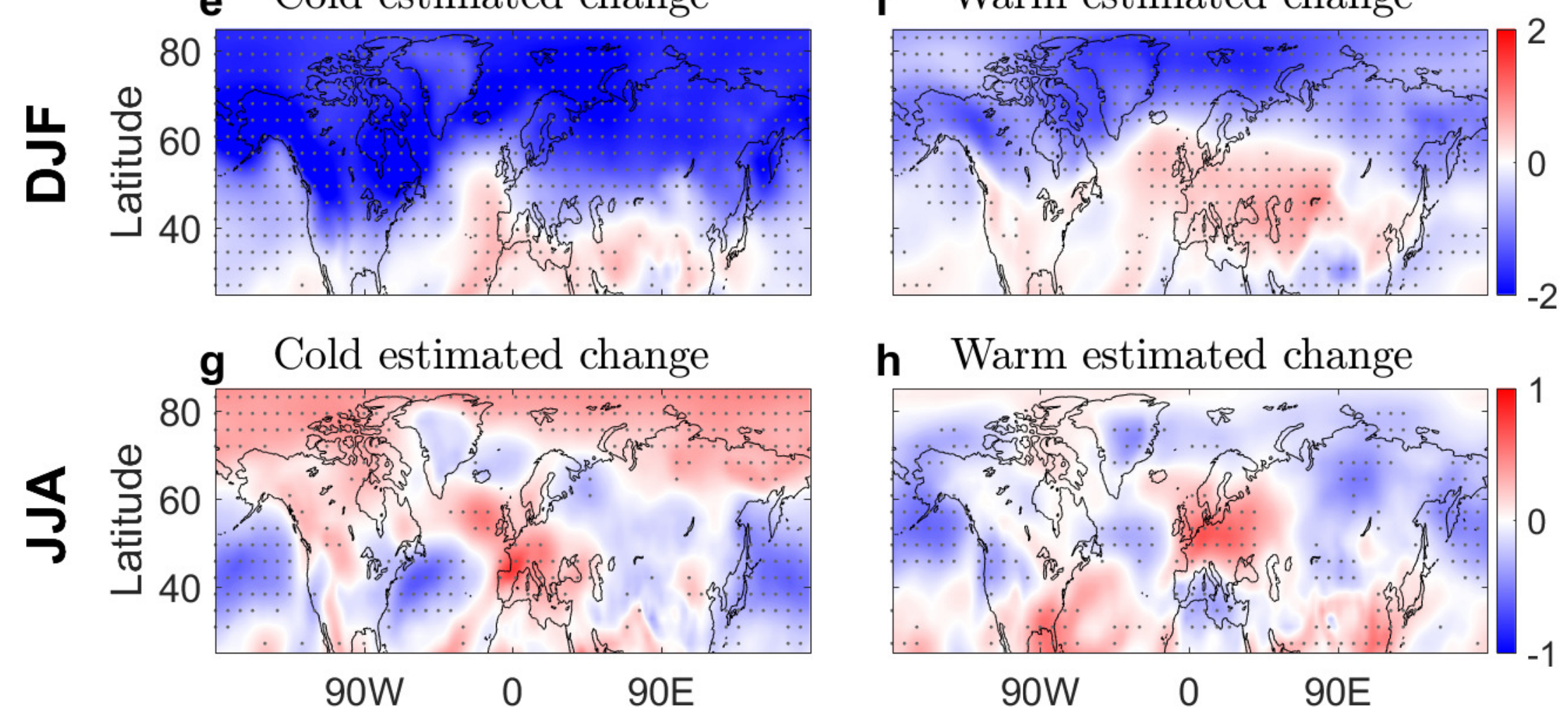

h Warm estimated change

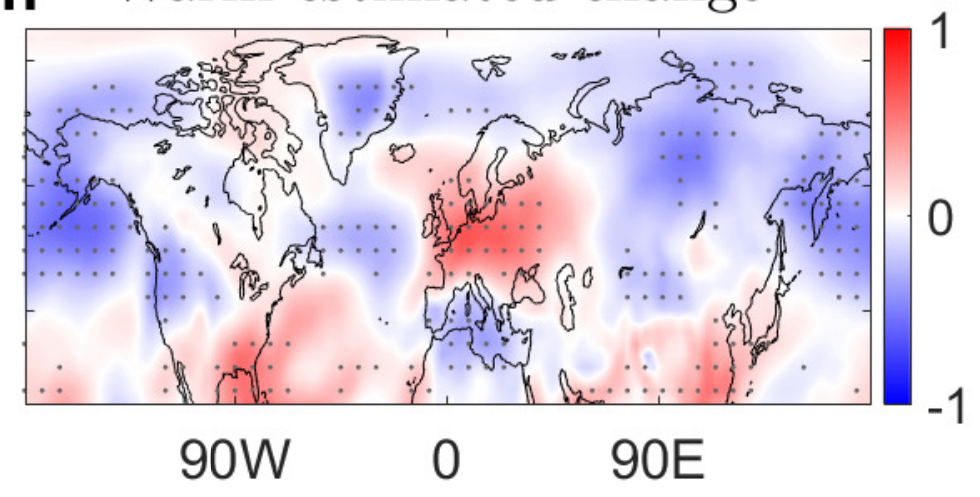




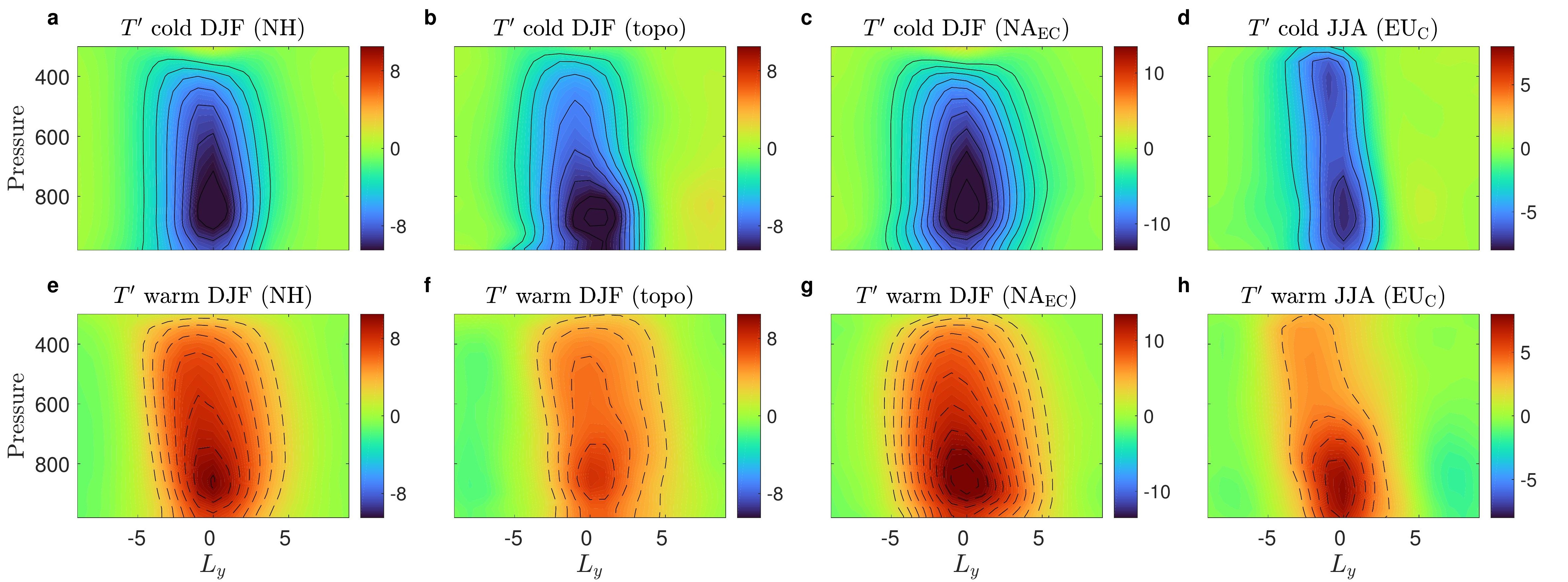




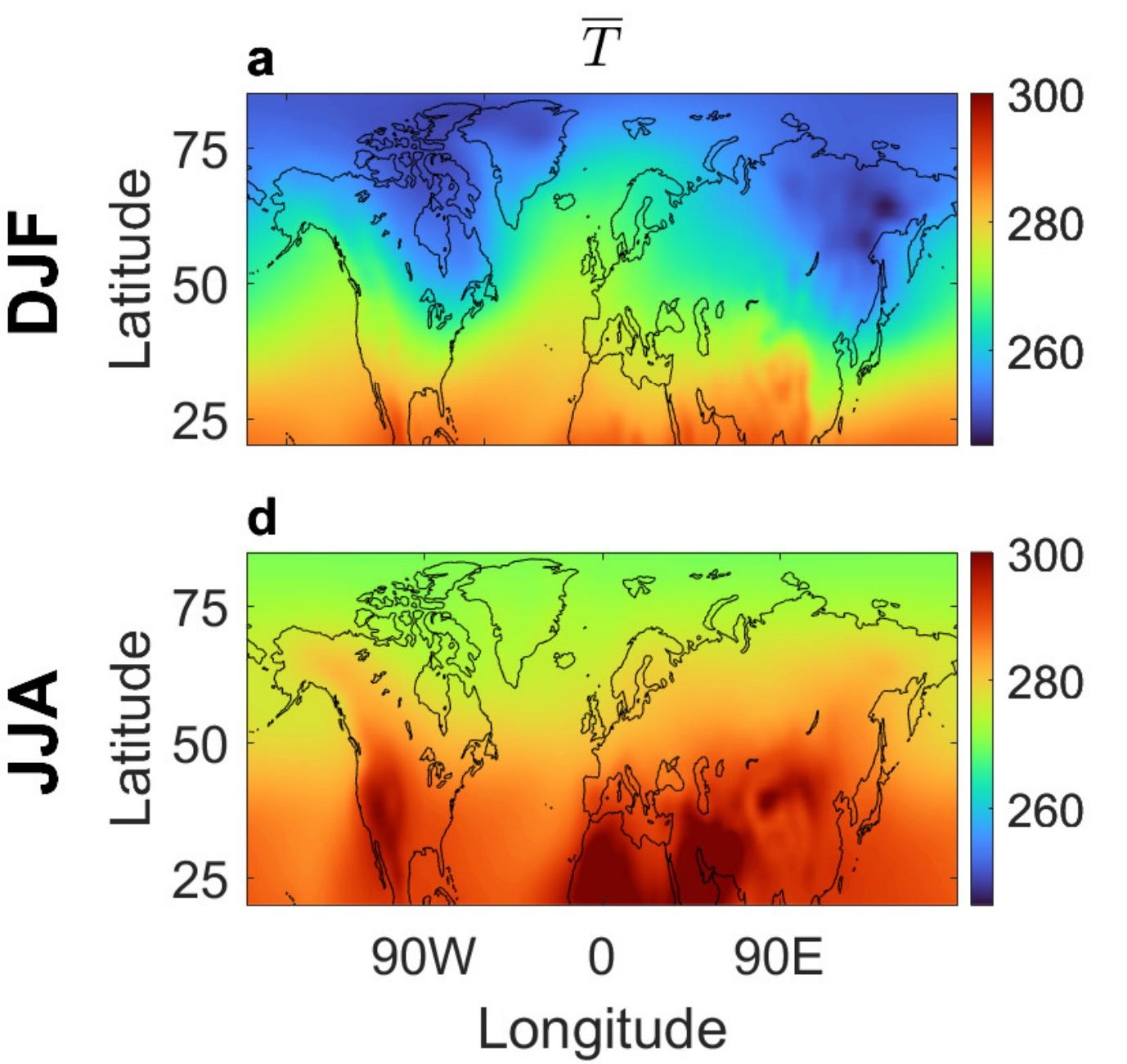

Skewness
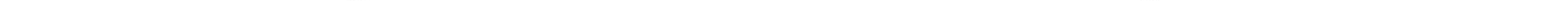

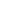
${ }^{\mathbf{a}}$ Risk Ratio $\left(\mathrm{NA}_{\mathrm{EC}} \mathrm{DJF}\right)$ cold

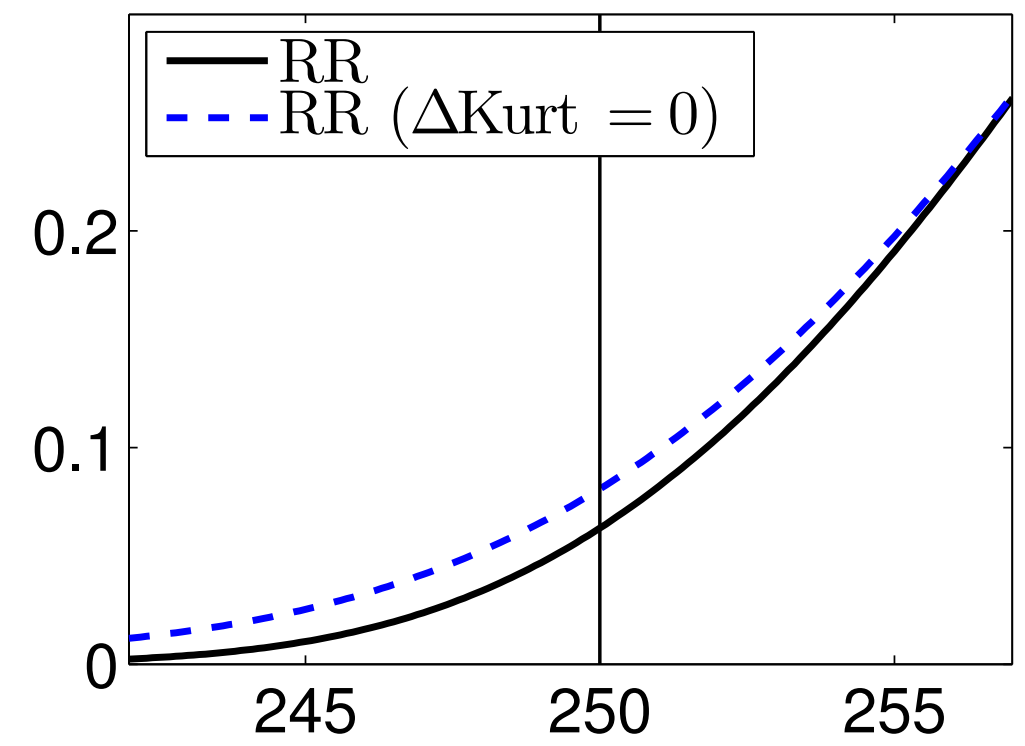

c Risk Ratio ( $\mathrm{E}_{\mathrm{C}} \mathrm{JJA}$ ) cold

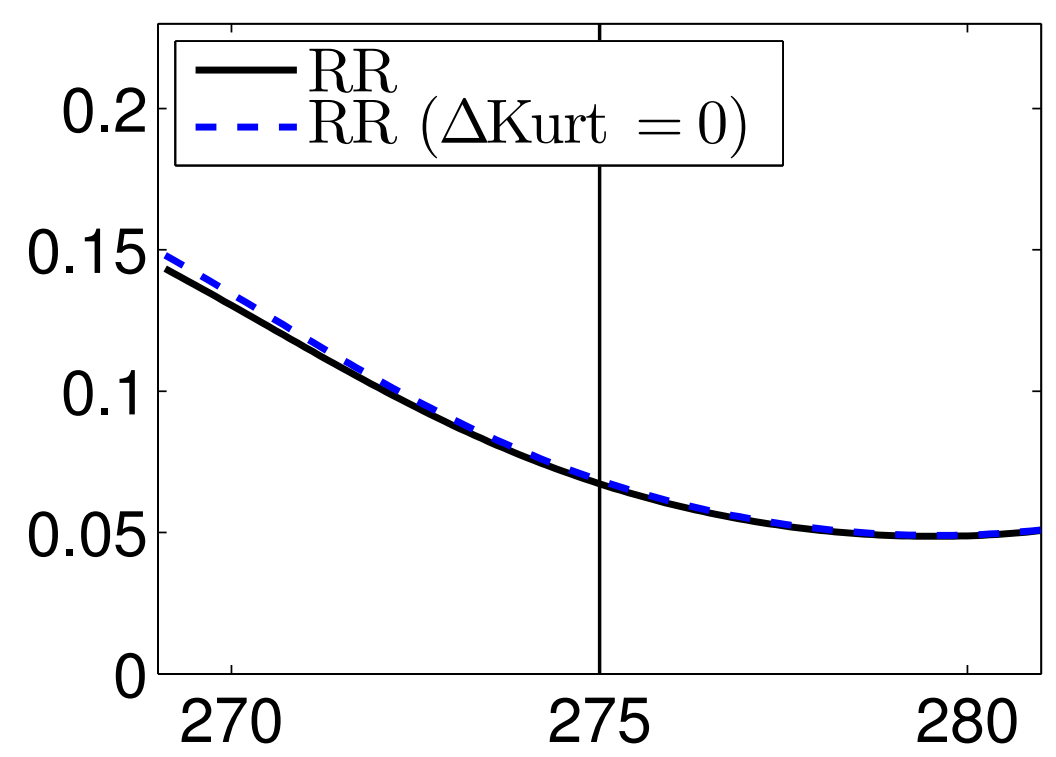

b Risk Ratio (NA $\mathrm{NC}_{\mathrm{EC}} \mathrm{DJF}$ ) warm

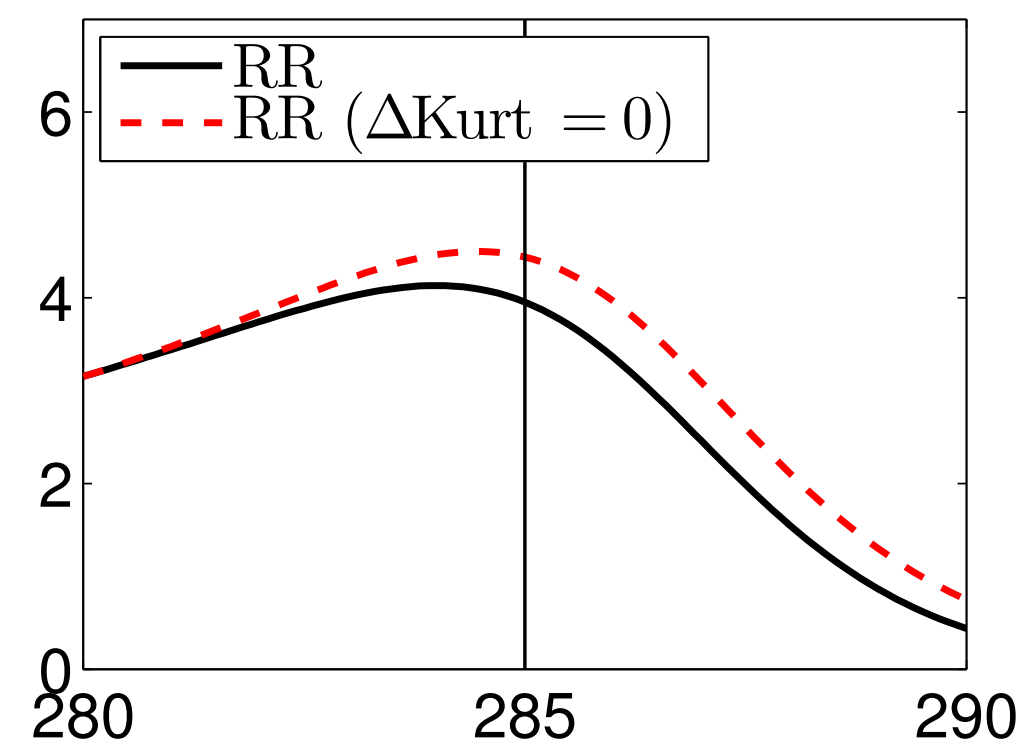

d Risk Ratio ( $\mathrm{E}_{\mathrm{C}} \mathrm{JJA}$ ) warm

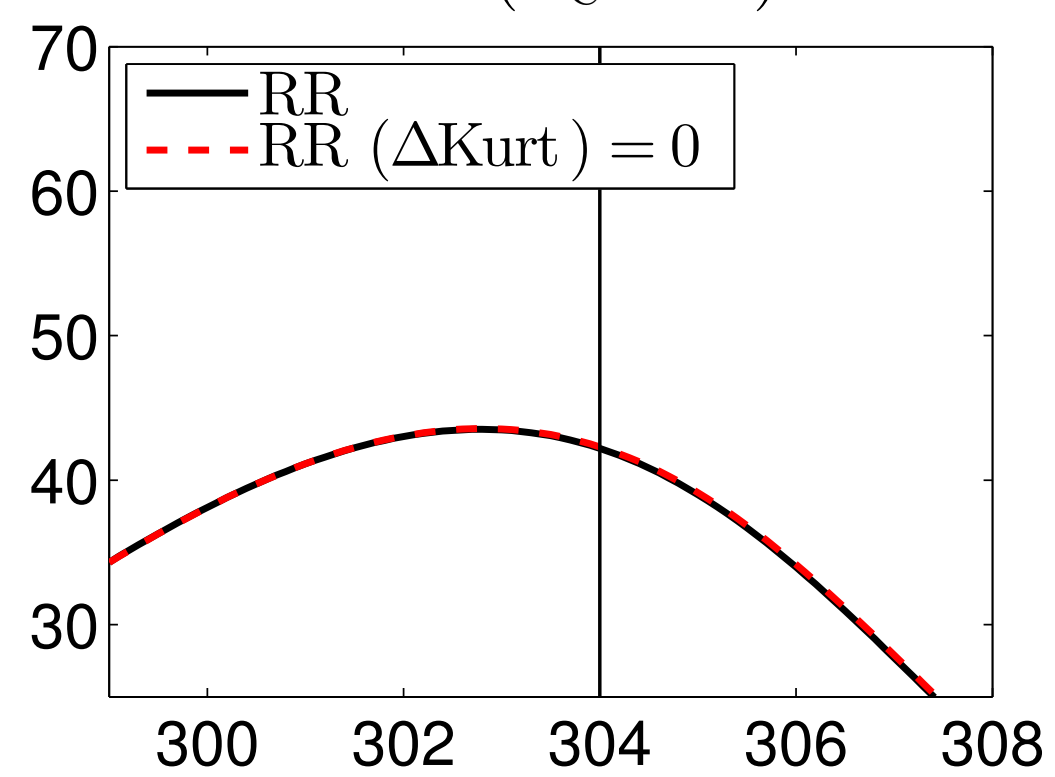



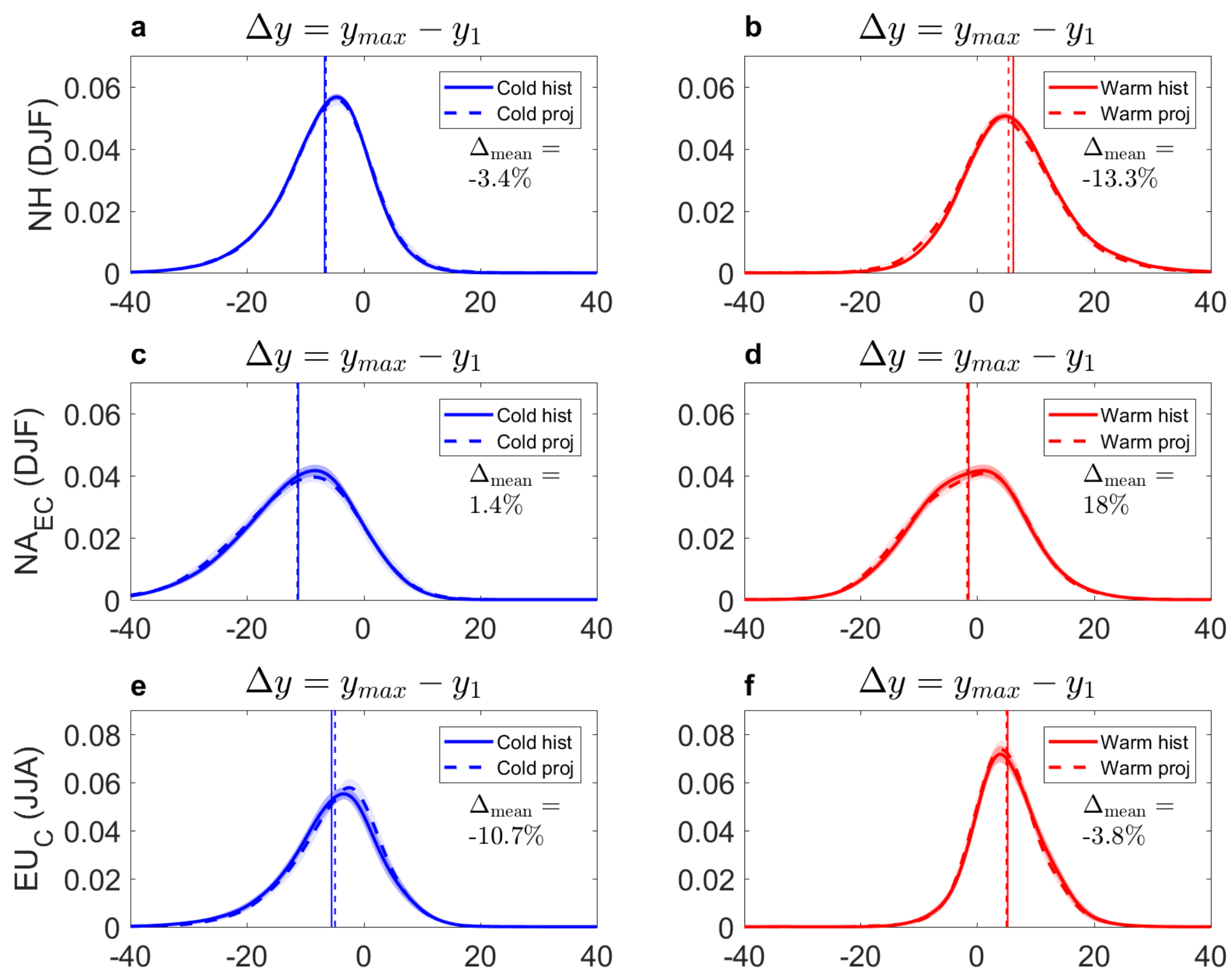
a $\quad T_{s}$ historical

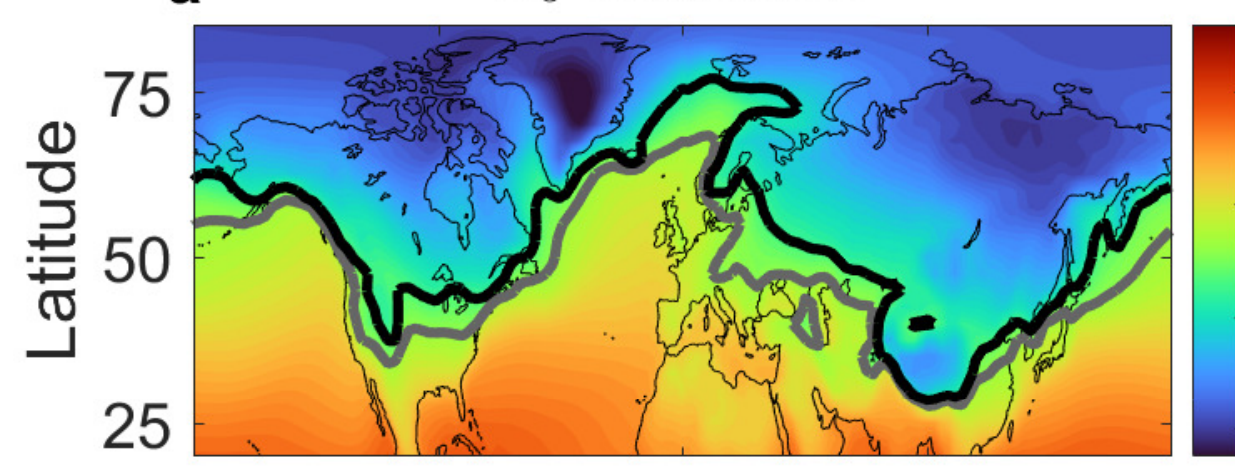

90W

0

90E

d $\quad T_{s}$ projected change

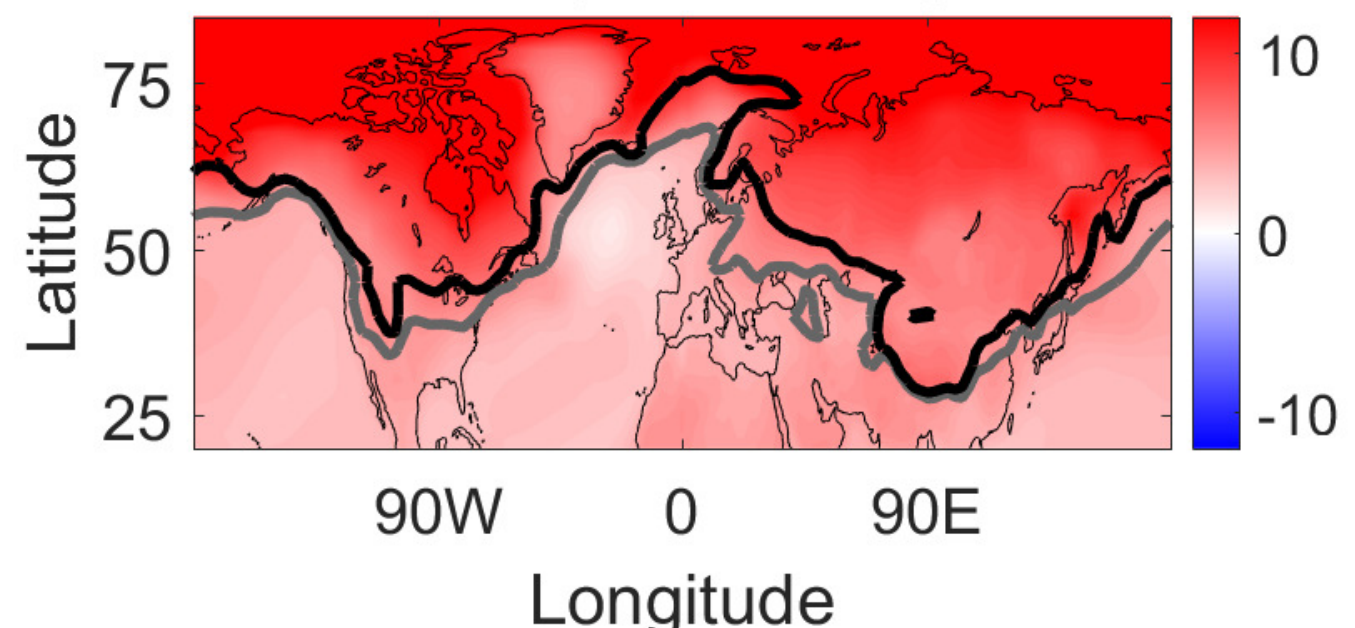

Longitude b $\quad T_{s}$ variance historical

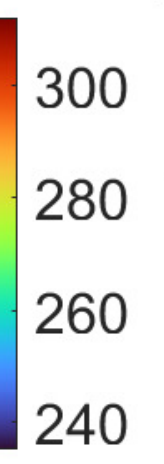

240

e $T_{s}$ variance projected change
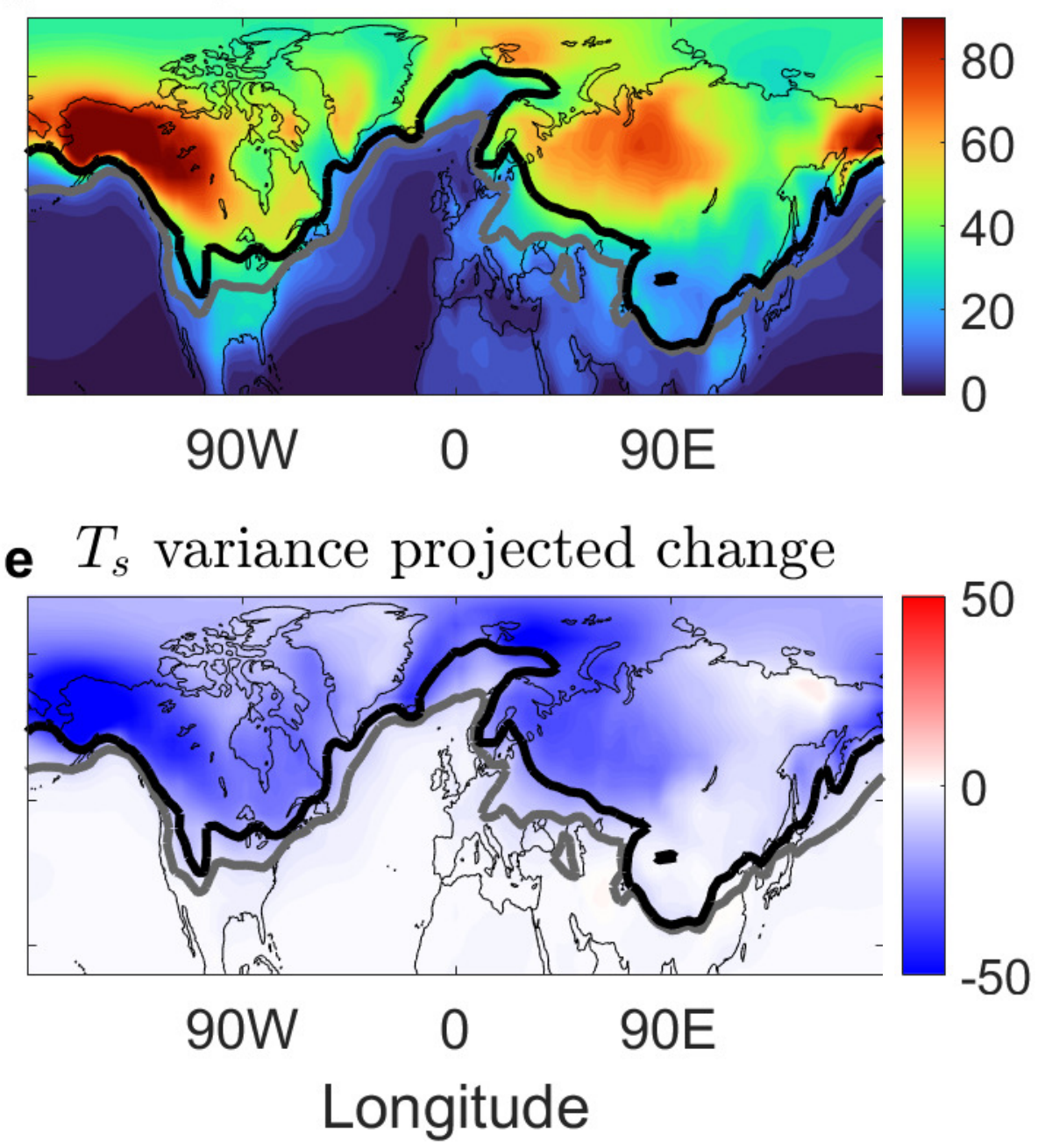

90W $0 \quad 90 \mathrm{E}$ c $\quad T_{s}$ skewness historical

90W

0

90E

f $T_{s}$ skewness projected change

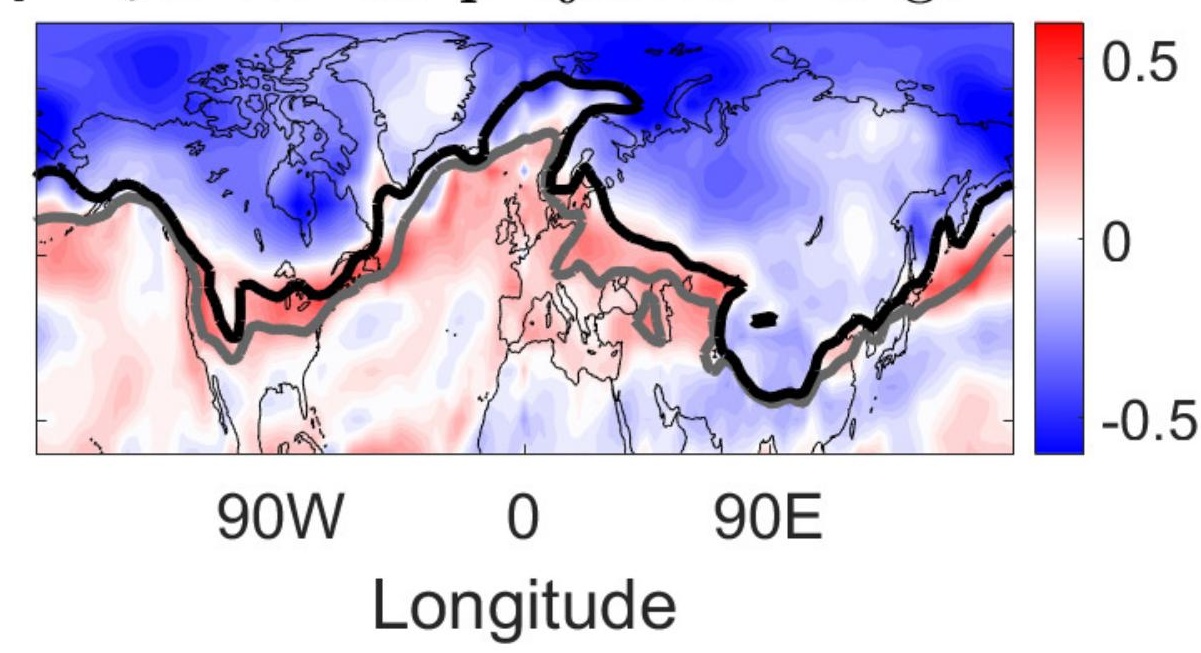




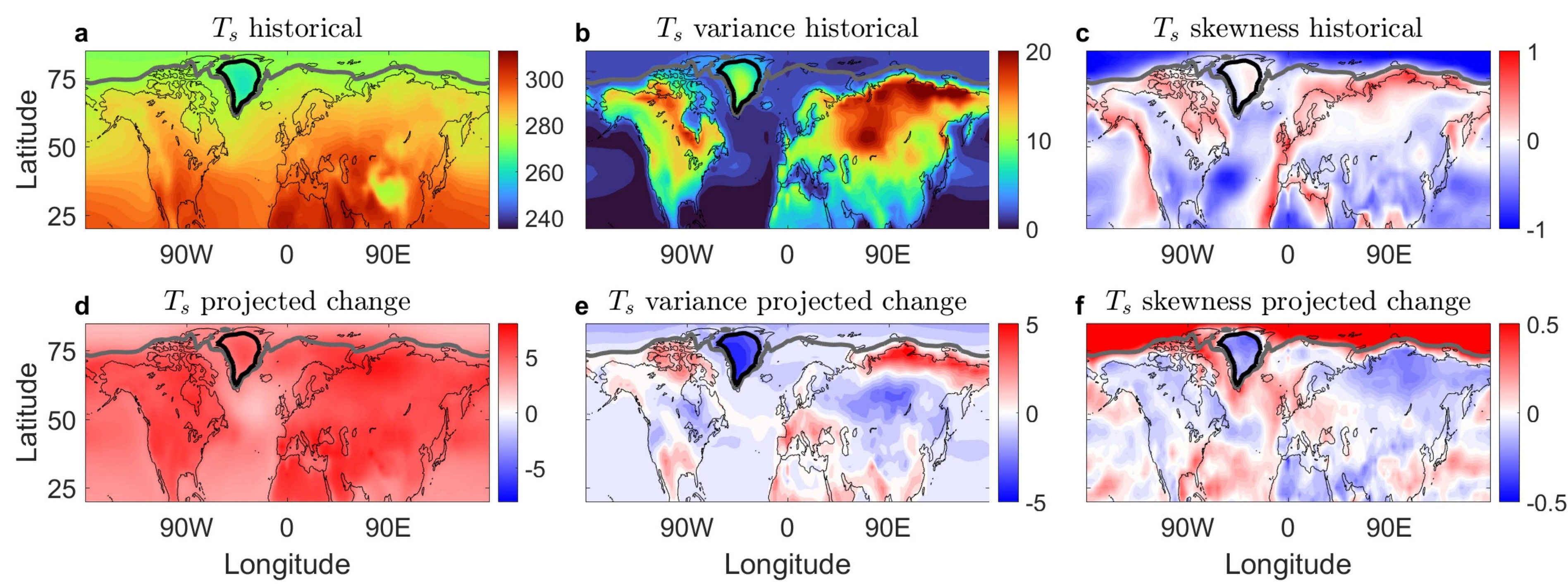

